\title{
TECHNOLOGY TRANSFER
}

AT

Viv

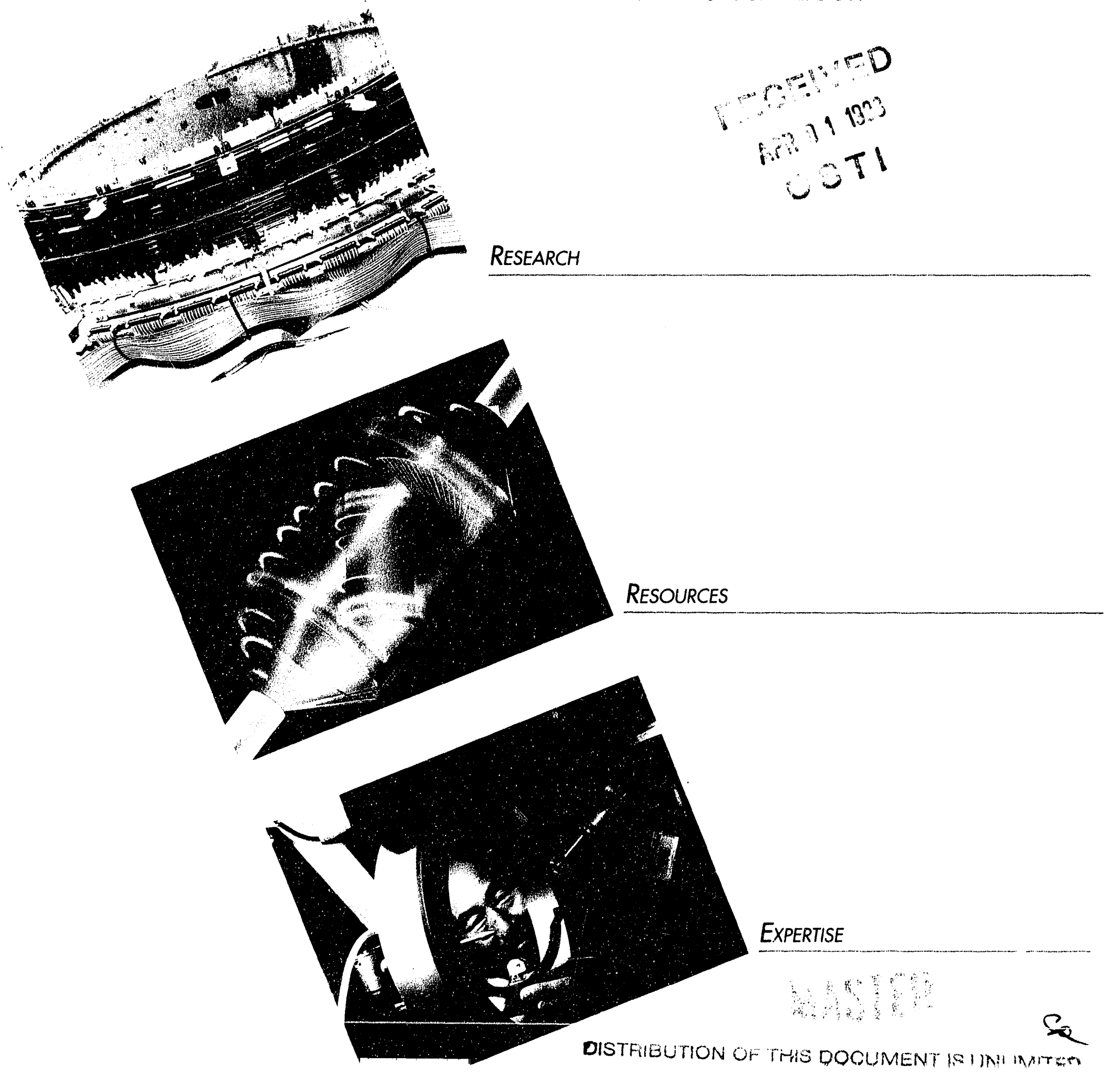

\section{Taking A Closer look}




\section{Cover Photos:}

Top photo-The LBL-designed end-cap uranium-liquid argon electromagnetic calorimeter for the 10 detector, a secondgeneration hadron collider detector. Its primary aim is the precision study of highmass, large-transverse-momentum phenomena, with particular emphasis on jets (clusters of produced particles), leptons (electrons and muons), and the "missing" transverse momentum indicative of penetrating particles, such as neutrinos.

Center photo-Schematic view of a "double rotation" sample holder. The design allows increased resolution in the nuclear magnetic resonance spectroscopy of a number of solid materials. Rotating the sample in the inner chamber, which in turn rotates in the outer chamber, will allow high-resolution study of nonspherical nuclei.

Bottom photo-The Nicolet P3 x-ray defractometer. This instrument measures the intensity of $\mathrm{x}$-ray diffraction from crystal specimens. LBL researcher Sung-Hou Kim is optically aligning a crystal specimen to hegin collecting data. X-ray diffraction measurement of crystals helps to determine the three-dimensional atomic structure of proteins, such as cancer-causing protein ras oncoprotein, and other molecules.

Prepared by the Technology Transfer Department Design concept, writer: Bruce Davies

Produced by the Technical Information Department Design and Layout: Marilee Bailey

Editor: Dick Johnson

Printing coordination: Jimmy Lovato

Photography (unless otherwise indicated): LBL Photographic Services 
Taking a Closer Look $\quad$

Profile-Lawrence Berkelev Laboratory 3

Technology Transfer Means Business $\quad 4$

Choosing Your Technology Transfer Vehicle 6

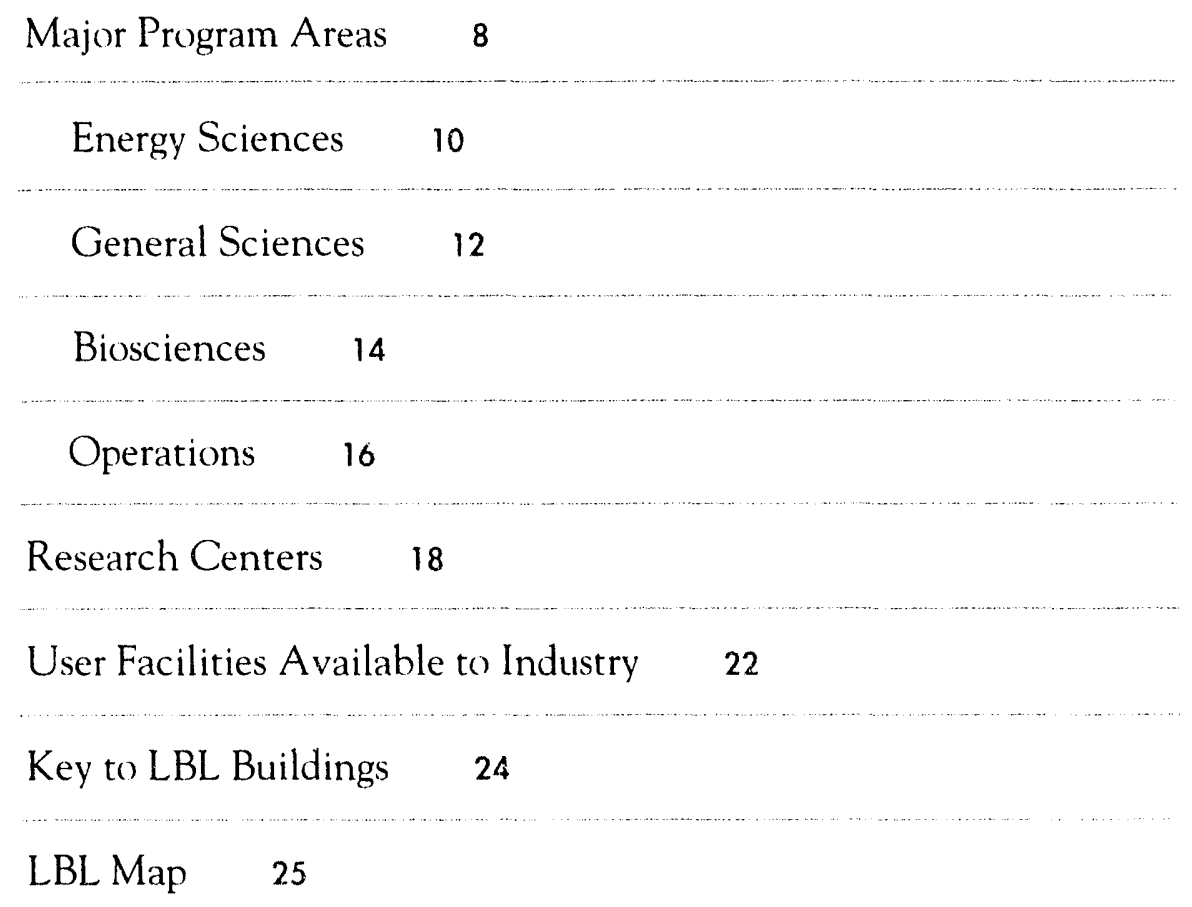




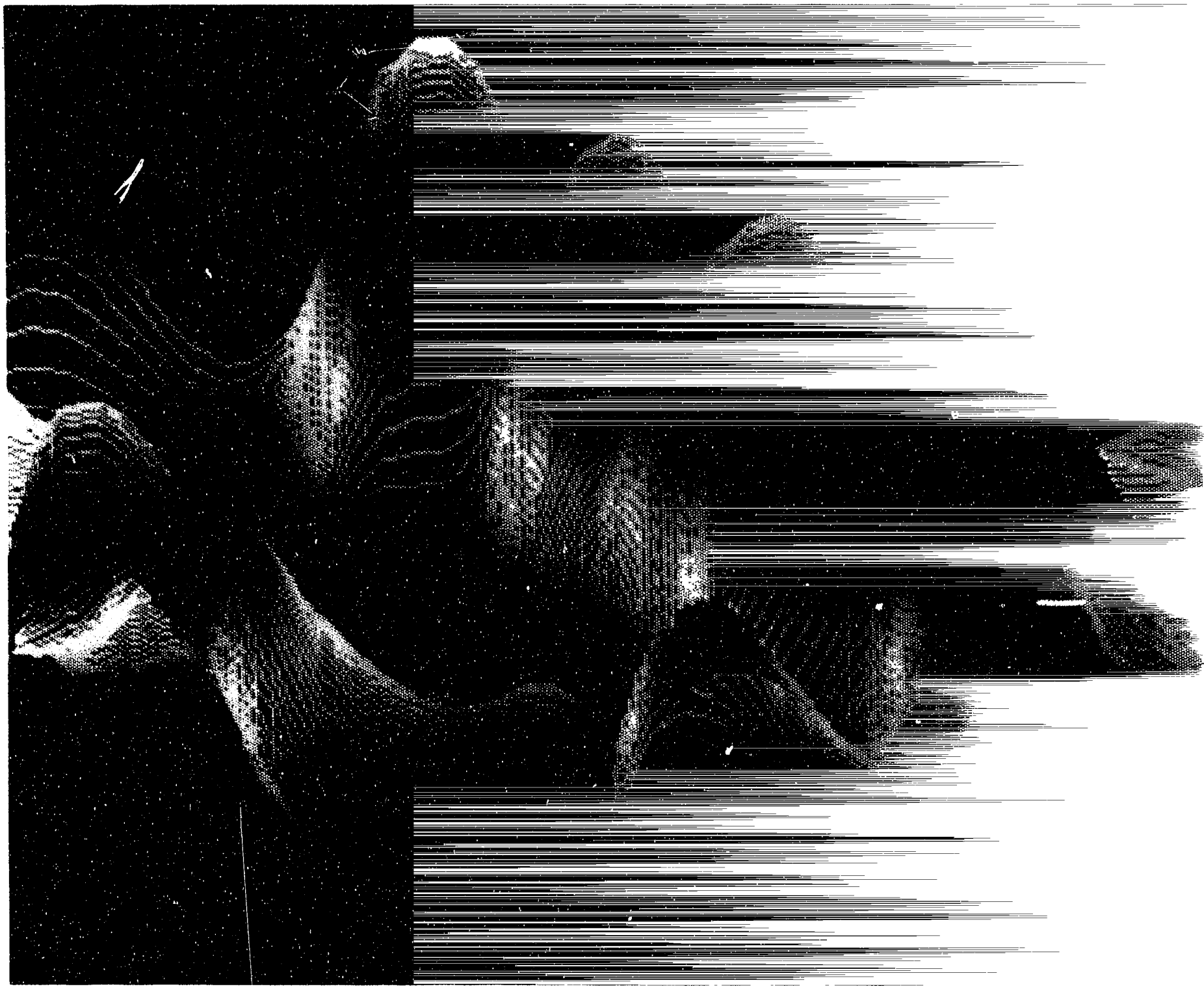

The first direct image of the helical structure of unaltered DNA was obtaned through a scanning tunneling micruscone at LBL', Center for Advanced Materials. The average distance between twists (shown as elevated contours in this isometric nrojection) is $35 \AA$ (vertical axis is $4 \times$ horizontal axis). 
In a rapidly expanding international marketplace, emerging technology drives the world's economy. The challenge to commercialize new technology will play out in fields such as advanced materials, biotechnology, and electronics, with the winner reaping worldwide economic rewards. Therefore, the value of technology transfer between national laboratories and the industrial community is more important in maintaining America's competitive edge than ever before.

- At Lawrence Berkeley Laboratory (LBL), we want to work with U.S. industry to meet this challenge. LBL will continue to emphasize research excellence while actively seeking and establishing working relationships with industry across the U.S.

- Our commitment to research innovation is the foundation for new high-potential technology applications.

- On the following pages we invite you to take a closer look at the many opportunities and ways to establish working relationships with LBL. The Laboratory encourages your inquiries: these may lead to an active alliance that delivers innovative solutions that create new technologies, products, and systems of value to society. 

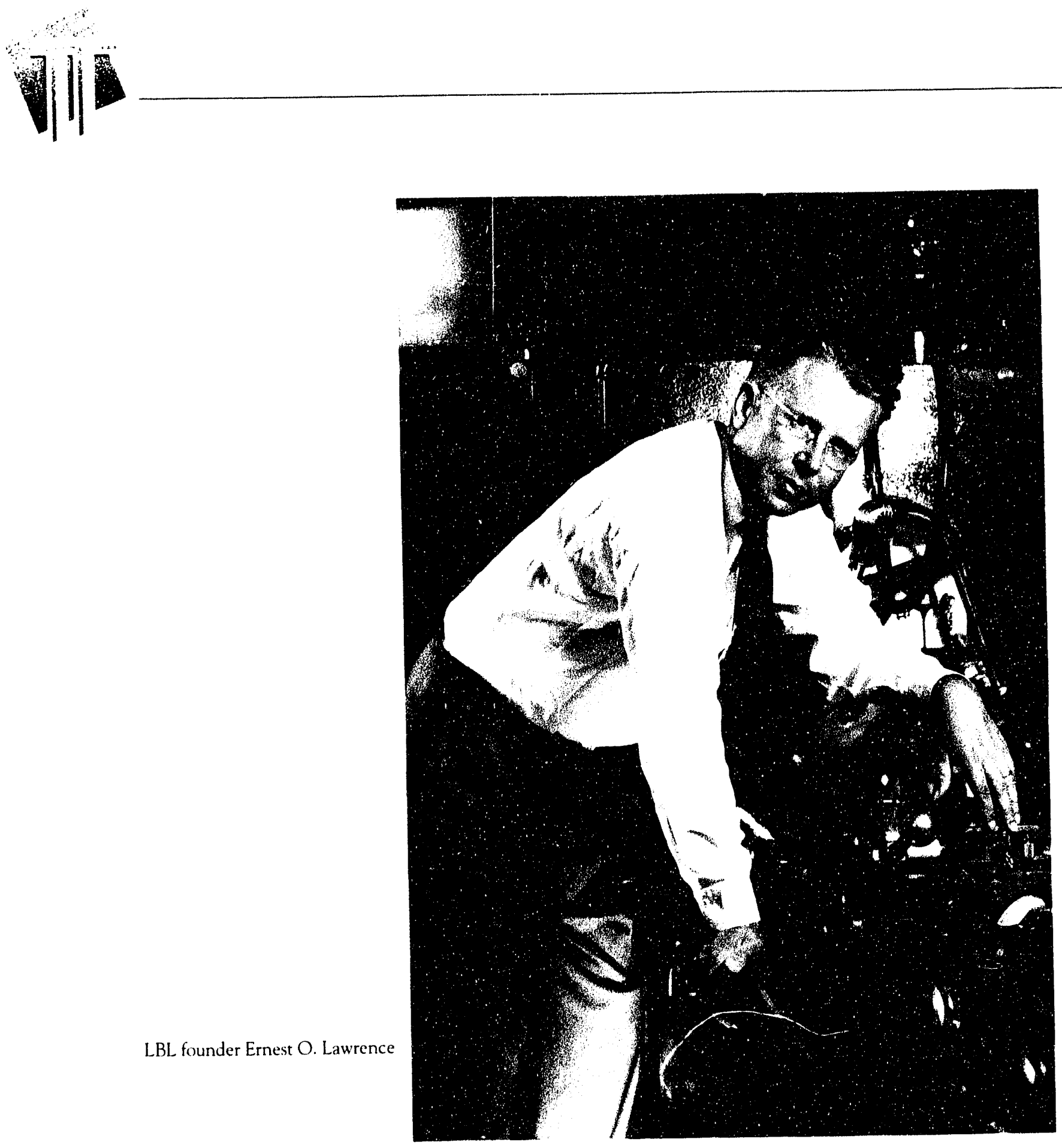
LAWRENCE BERKELEY LABORATORY

- LBL is a major multiprogram national laboratory managed by the University of California for the U.S. Department of Energy (DOE). LBL has more than 3,000 employees, of which 950 are scientists, theoreticians, and engineers. With an annual budget of over $\$ 250$ million, LBL conducts a wide range of research activities, many that address the long-term needs of American industry and have the potential for a positive impact on U.S. competitiveness.

- The oldest of the nine DOE national laboratories, LBL is located next to one of the world's great universities-the University of California at Berkeley. This environment attracts some of the world's best and most creative investigators. Principal research programs include materials science and chemistry, earth sciences, biology and medicine, conservation and renewable energy, high-energy and nuclear physics, as well as engineering, mathematics, and computer sciences. Using multidisciplinary approaches to conduct research, teams of LBL scientists, theorists, engineers, and technicians employ state-of-the-art equipment to tackle and solve complex technological problems.

- LBL's role is to serve the nation and its scientific, educational, and business communities through research and development in the energy sciences, biosciences, and general sciences; to develop and operate unique national experimental facilities for use by qualified investigators; to educate and train future scientists and engineers; and to develop productive relationships between $\mathrm{LBL}$ research programs and industry. 


\section{Technology Transfer Means Business}

Lawrence Berkeley Laboratory invites you to take a closer look at the many RED approaches and opportunities available to private industry.

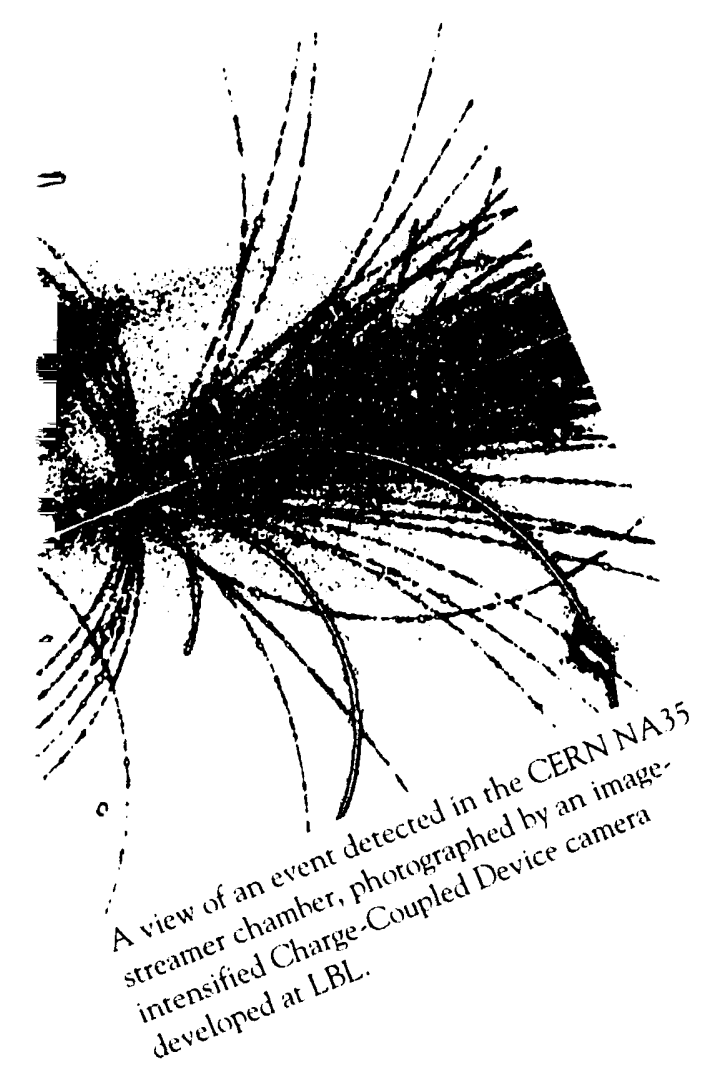

\section{LBL Welcomes Your Inquiries}

The research areas and administrative structure described in this publication provide general guidelines. LBL's interdisciplinary science approach offers many technology transfer options. DOE policy encourages private-sector use of government-developed technologies. $\mathrm{LBL}$ welcomes your inquiries to explore areas of research, technology, and collaboration.

\section{Forging Stronger Ties}

As a national laboratory, one mission of $L B L$ is to make research results available to the nation's private sector for rapid commercialization. Private industrialists and entrepreneurs broaden the potential benefit and commercial value of laboratory research. They help translate new discoveries into commercially usable products and processes. Working together, the national laboratories and U.S. industry can help strengthen America's competitiveness in the world marketplace-together, we mean business.

\section{Making Technology Transfer Accessible}

To help make effective the transfer of technology from LBL to industry, LBL has streamlined its technology transfer operations. The following departments interact to help move technology and ideas to the marketplace and to ha. aule research proposals and contracts with outside sponsors. 


\section{Technology Transfer Department}

The role of the Technology Transfer Department is to make technology and expertise developed at LBL available to industry.

Technology transfer depends on communication between those generating knowledge and those able to put it to use. The Technology Transfer Department acts as a focal point to foster productive relationships between $\mathrm{LBL}$ research programs and the private sector. If you have questions regarding research areas of interest or wish to have an answer regarding working relationships with LBL, start with the Technology Transfer Department. Call or visit the Technology Transfer Department to

- Pinpoint research areas of common interest

- Negotiate rights to LBL's intellectual property

- Discuss current patent and copyright licensing opportunities

- Set up meetings with specific investigators; arrange LBL tours

- Learn the names of people in charge of sponsorships, collaborative projects, and staff-exchange programs

\section{Patent Department}

As part of the Technology Transfer Department, the Office of Sponsored Research Administration (OSRA) is the administrative liaison for sponsored research and research collaborations beween LBL scientists and the private sector. If your company would like to use LBL facilities or have work performed by or jointly with LBL investigators, contact OSRA. OSRA's experienced staff coordinates proposal submissions and contract negotiations. Call or visit OSRA to inquire about

- Research performed by LBL scientists under sponsorship by industry

- Use of LBL User Facilities by industry personnel

- Collaborative researchsharing of LBL and industry costs, facilities, equipment, or research capabilities

- Industry support of LBL researchers through gifts, graits, or fellowships

- Proposal submissions

- Contract negotiations
The function of the Patent Department is to protect LBL inventions, technology, and software.

Staffed by professional patent attorneys, the Patent Department performs the legal work of $\mathrm{LBL}$ in matters relating to LBL inventions. It also performs an advisory and service role for the Technology Transfer Department and the Office of Sponsored Research Administration. To carry out its function, the Patent Department

- Pursues patents, evaluates patentability of LBL inventions

- Creates, files, and prosecutes patent applications

- Registers copyrights with the U. S. Copyright Office

- Approves all intellectual property-rights clauses in sponsorship contracts and licensing agreements

- Interacts with DOE to expedite transfer of patent rights to the private sector 


\section{Choosing Your Technology Transfer Vehicle}

LBL's research produces innovative technologies and inventions, many with commercial value. LBL's resources, expertise, and project-oriented teams can help make your company's RED effort more effective. From acquiring written information on a special project to establishing research collaborations or licensing available technology, there are many ways to work with Lawrence Berkeley Laboratory-many ways to leverage your research activities.

\section{Licensing New Technology}

LBL's work produces innovative and inventive discoveries, many of which have commercial value and are available for licensing. To discuss licensing possibilities, ideas for new technology applications, markets, or products-contact the Technology Transfer Department.

\section{Sponsored Research}

A company may sponsor LBL scientists to perform specific research compatible with LBL's research in the company's field of interest. The unique equipment and specialized staff expertise at LBL provide research opportunities that would not otherwise be available. Discuss research concepts with scientific staff. To coordinate efforts-contact OSRA.

\section{Visitor/Staff Exchanges}

University and industrial scientists may visit LBL to conduct research. Each year DOE sponsors a Laboratory-Industry Exchange Program, offering opportunities for researchers from industry and DOE laboratories to work in areas of mutual interest and benefit at one another's sites. For more information about this program-contact the Technology Transfer Department or the appropriate research division. For visits or staff exchanges that require a contractual relationship-contact OSRA. 


\section{Collaborative Research and Development Agreements (CRADAs)}

Some of the most innovative technology transfer at LBL today involves collaborative projects with industry. In collaborative research arrangements, DOE and industry jointly sponsor a research

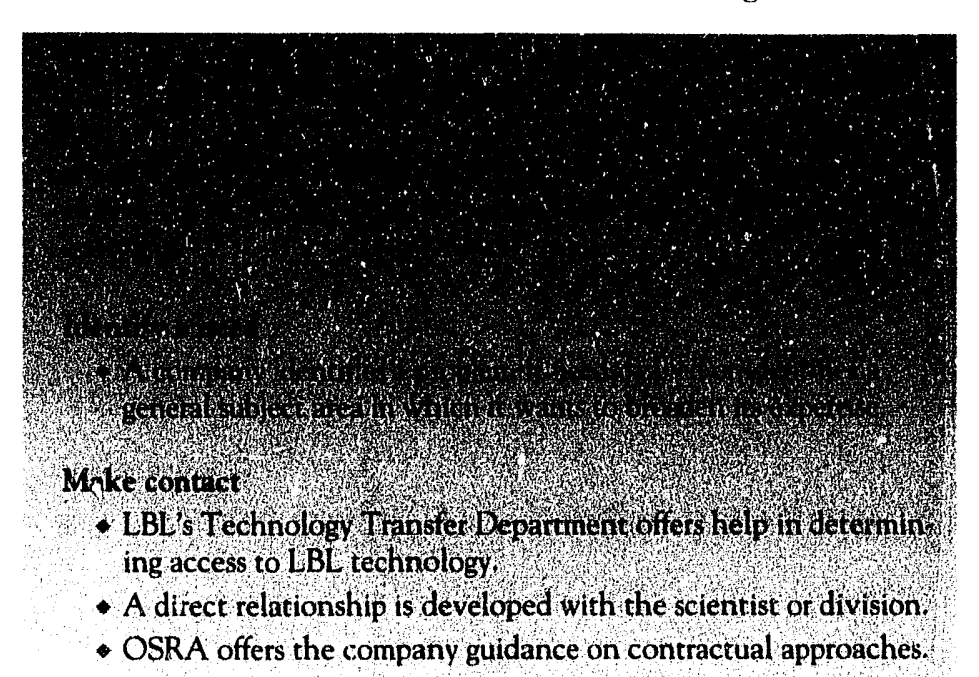

Initiate discussion

- A dialogue between the company and LBL technical managers is initiated.

- Contractual and administrative terms are discussed with OSRA.

- Intellectual property matters are discussed with the Technology Transfer Department.

\section{Choose a velicle}

- A choice is made regarding a technology transfer method that will produce the desired results.

- Administration of industrially sponsored research and research collaboration projects are finalized with OSRA. project. Costs, personnel, facilities, equipment, or research capabilities may be shared for mutual benefit. This provides industry with an excellent way to leverage research activities. Discuss technical points with scientific staff. Contact OSRA for proposal, contractual, and administrative matters. Discuss intellectual property arrangements with the Technology Transfer Department.

\section{Gifts and Graduate Support}

Gifts to LBL are received in the form of equipment, research materials, and funds. Gifts may be undesignated or may be designated for a particular research area or research group. A fellowship may be given to support a graduate student's research. If a company is interested in acquiring expertise in a particular area, a specific student may be supported with the intention of bringing the student into the company after graduation. This is an efficient way to transfer technological expertise from LBL. To coordinate gifts and fellowship support-contact OSRA .

\section{User Facilities}

Certain facilities at LBL and other DOE laboratories are considered "National User Facilities" offering unique opportunities. User Facility arrangements are administered through OSRA.

User Facilities are discussed in further detail on page 22 . 
Research activities at LBL are concentrated in three major program areas: Energy Sciences, General Sciences, and Biosciences. Each program area consists of three research divisions. Program areas are supported by a technical resource division. The following section offers brief descriptions of the divisions and their areas of expertise. Comprehensive overviews of research performed at each division are available from $\mathrm{LBL}$. Lawrence Berkeley Laboratory welcomes both requests for information and proposals to conduct research.

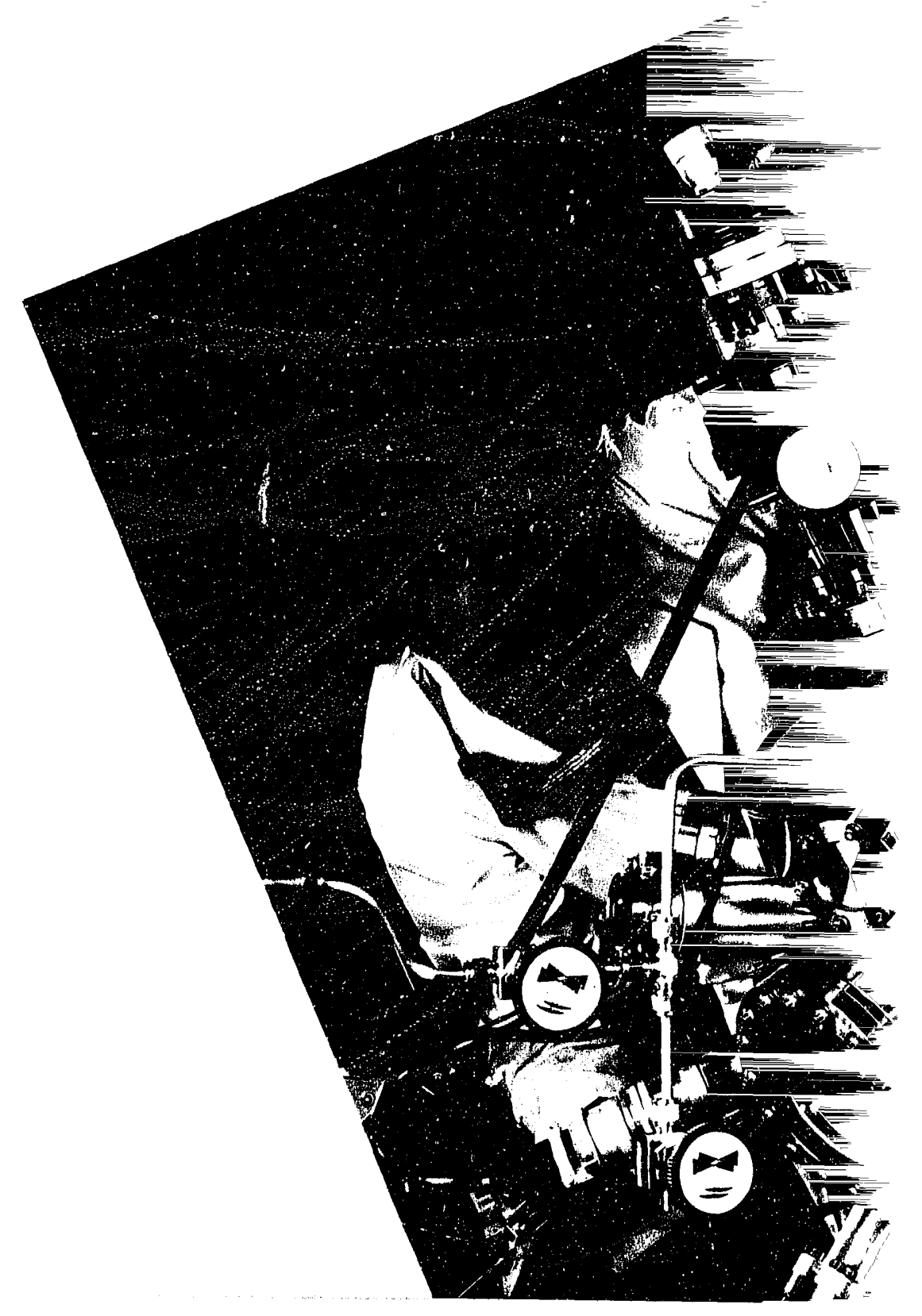




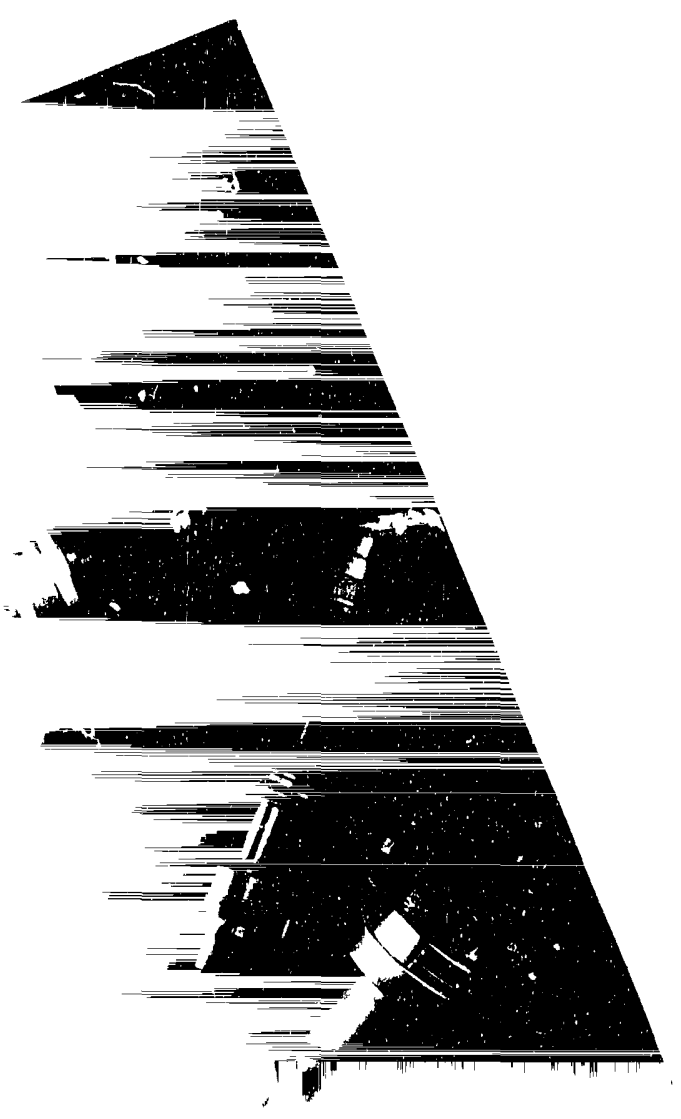

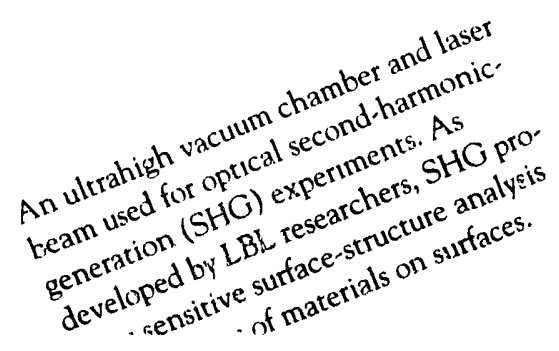




\section{ENERGY SCIENCES}

Energy Sciences research at $\mathrm{LBL}$ encompasses a wide spectrum of energy sciences and technology that includes programs in materials science, chemistry, physics, geology, and engineering. Energy resources, energy conservation, waste disposal, and the impact of energy technology on the environment are explored.

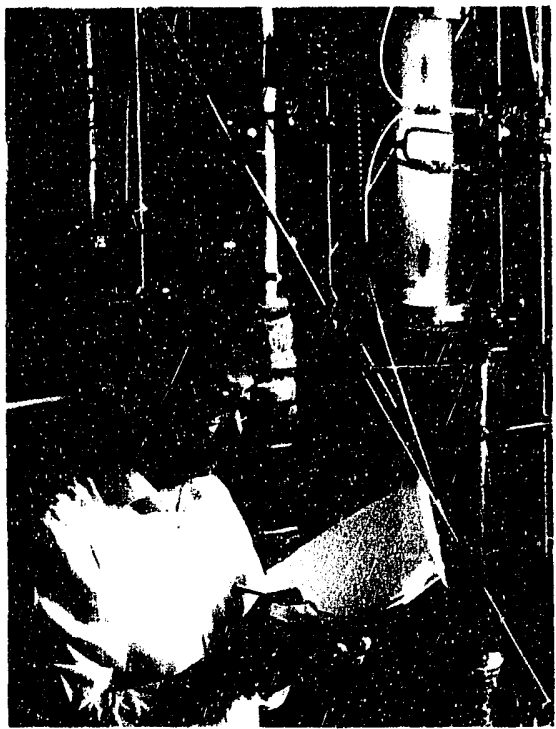

Energy and Environment. Researcher Ted Chang works at a bench-scale scrubber whose technology could costeffectively remove more than $90 \%$ of the $\mathrm{SO}_{2}$ and $\mathrm{NO}_{x}$ emitted (as flue gases) from coal-fired power plants.

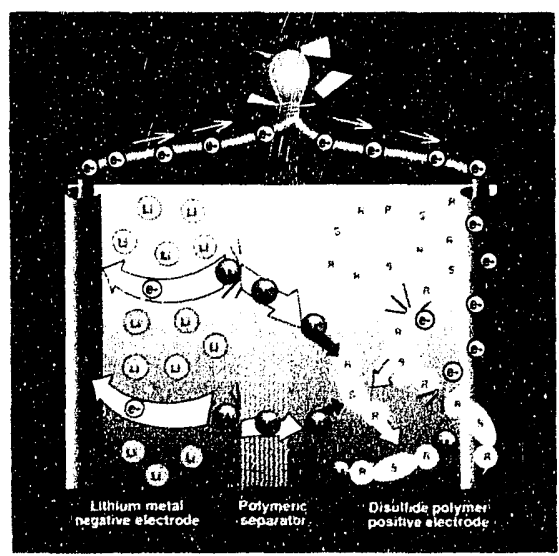

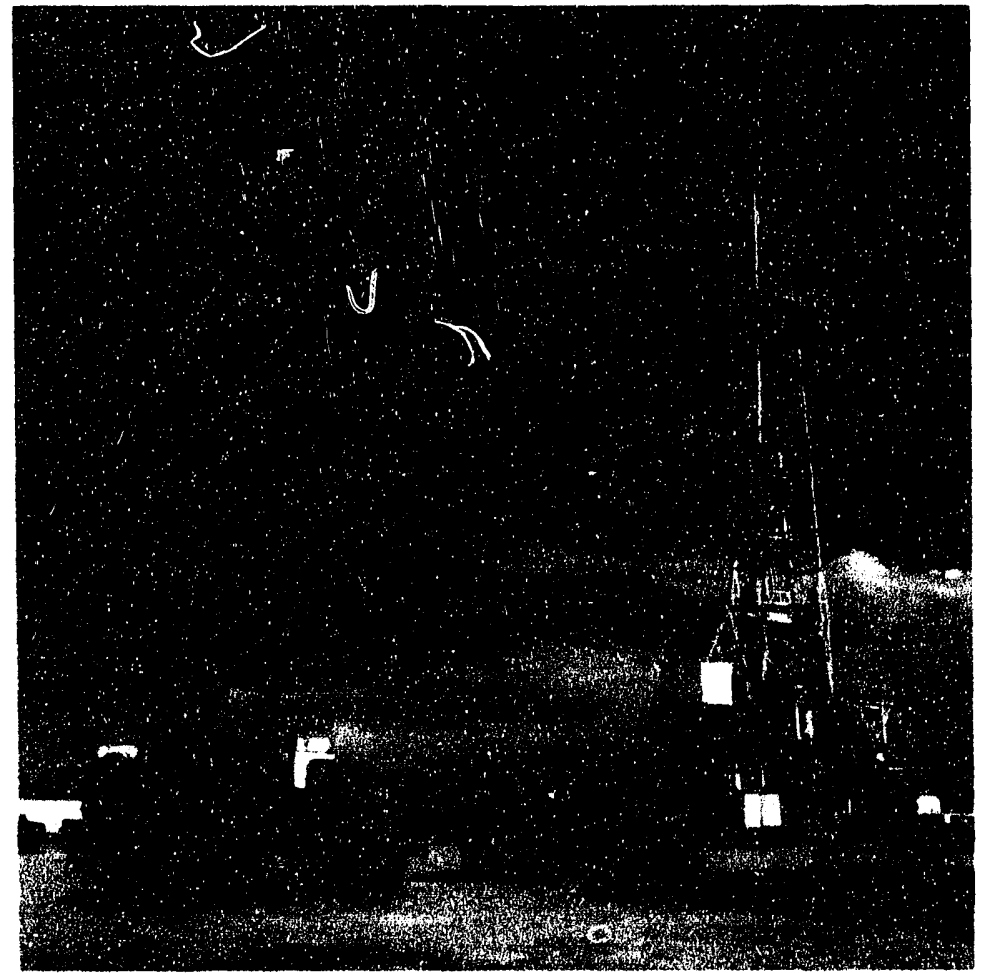

Earth Sciences. Vertical seismic profile survey underway at the Salton Sea Scientific Drilling Project drill site. The two large vehicles are compressional $(P)$ and shear $(S)$ wave vibrators used to generate seismic wave signals.

Materials Sciences. LBL researchers invented a novel all-solid-state rechargeable battery. It uses a new class of polymer cathodes based on redox polymerization and depolymerization. LBL's solid-state lithium hattery technology has been licensed to a U.S. company. 


\section{Energy and Environment Division}

Research conducted in Energy and Environment covers a broad spectrum of areas, with emphasis on providing environmentally acceptable energy options for the future. These include fuels from nonpetroleum sources, advanced batteries, conversion of solar energy, and improvements in energy end-use efficiency. The research on energy conservation in buildings, energyefficient lighting, indoor air quality, solar heating and cooling, and acid rain continue to produce results that enlighten and inform both the public sector and the scientific community.

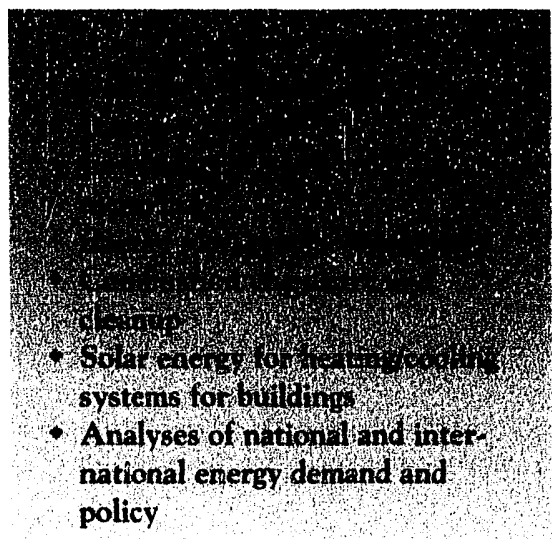

\section{Research Centers}

- Center for Building Science

- California Institute for Energy Efficiency

- Center for Atmospheric and Biospheric Effects of Technology

- Berkeley Electrochemical Research Center

\section{User Facilities}

- Sky Simulator for Architectural Daylighting Design

- Mobile Window Thermal Test Facility

\section{Earth Sciences Division}

Investigators in Earth Sciences study the underground environment to accumulate knowledge essential for safe disposal of radioactive and toxic chemical wastes, to exploit geothermal energy, and to develop petroleum and strategic-mineral resources.

Comprehensive research is conducted on the effects of high temperature and pressure on geological materials; the structure and dynamiss of the Earth's deep crust and the influence of crustal processes on energy resources; and the behavior of fractured rock formations encountered in mining, geothermal, petroleum-extraction, or waste-disposal activities.

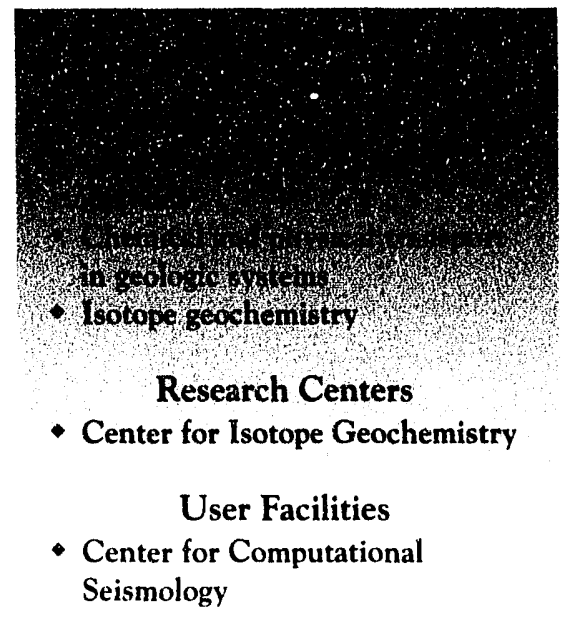

\section{Materials Sciences Division}

Investigators in Materials Sciences conduct both experimental and theoretical research on a wide range of materials, including high-temperature superconductors, composites, catalysts, ceramics, polymers, biomaterials, and electronic, magnetic, and optical materials. Work includes studying the electronic, structural, and other properties of thin films, surfaces, interfaces, and bulk materials; developing the science of wear, fracture, anc failure modes; extending the understanding of catalysts, including enzymes; obtaining atomic scale control of materials synthesis and processing; and innovating advanced materials characterization techniques and instrumentation.

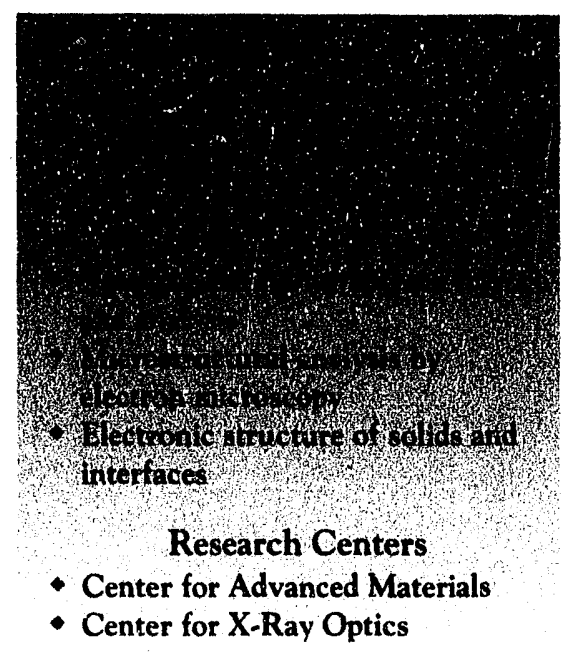

User Facilities

- National Center for Electron Microscopy

- 2.5-MeV Van de Graaff Facility

\section{Chemical Sciences Division}

The Division conducts research on chemical reaction mechanisms and dynamics in the gas and condensed phase, synthetic chemistry, actinide chemistry, homogeneous and heterogeneous catalysis, thermodynamics and phase equilibria, surface science, and atomic physics. The Division also hosts a rnajor new LBL initiative in combustion dynamics.

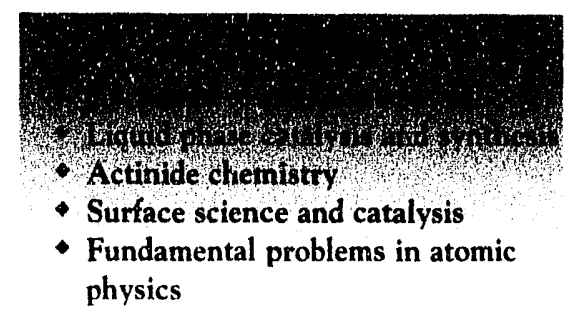




\section{GENERAL SCIENCES}

The Generill Sciences research programs build on LBL's historical work in high-energy physics, increasing our fundamental understanding of the nature of matter and providing a scientific and educational base for other fields.

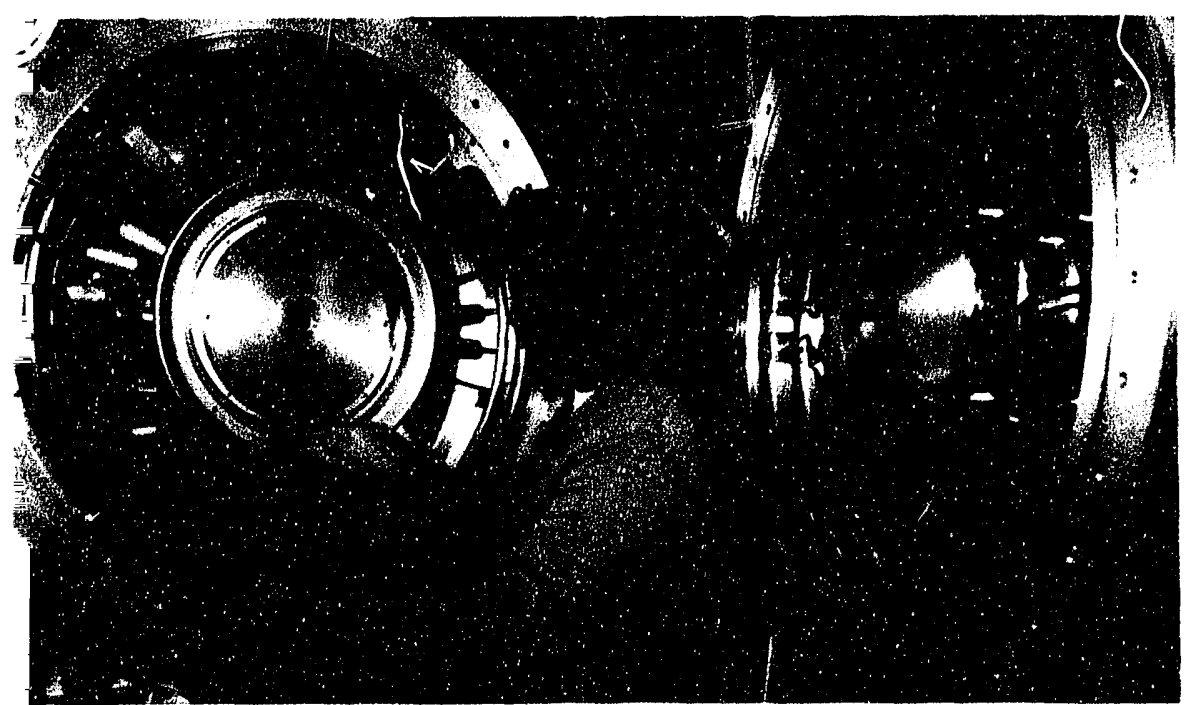

Acceleratur and Fusion Research. The constant-current, variablevoltage accelerator, developed by the Magnetic Fusion Energy Group, features electrostatic quadrupole focusing that reduces the risk of voltage breakdown.

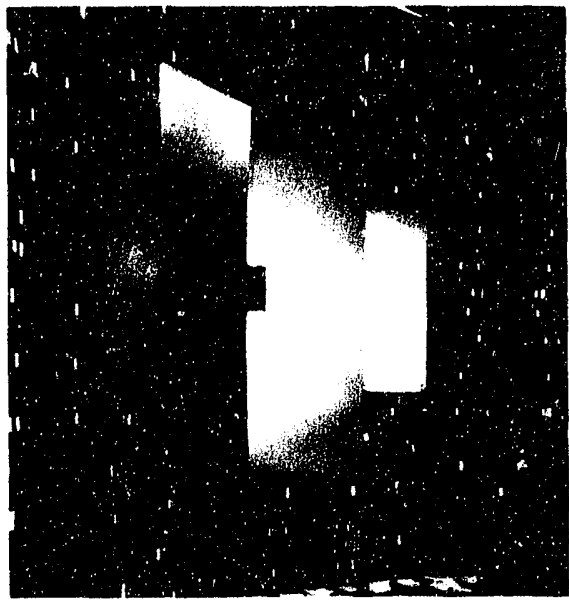

Nuclear Science. This array of plastic detectors was used by Kent State scientists to detect neutrons in coincidence with charged particles in a central heavy-ion collision.

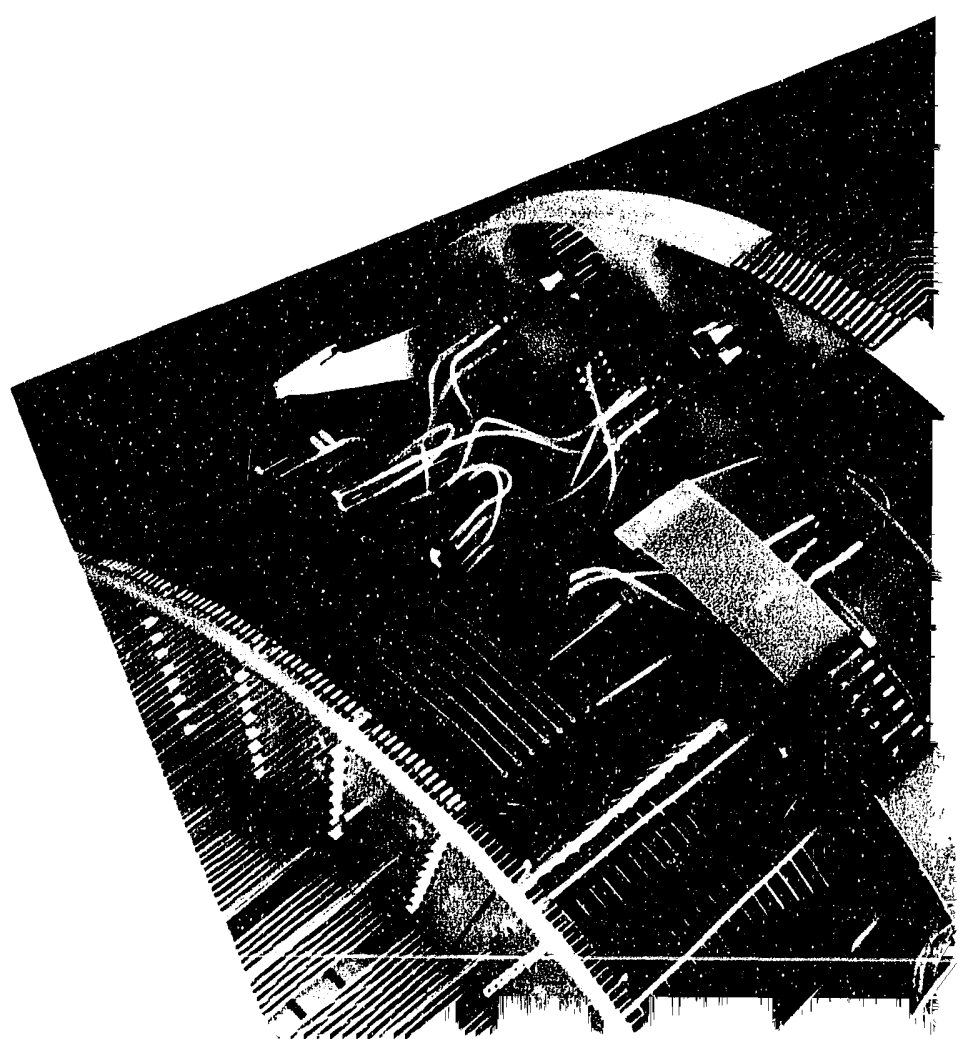




\section{Physics Division}

The Divisiun carries out research in experimental and theoretical particle physics, while developing new tools and techniques needed in the study of high-energy particle interactions. The Division's Particle Data Group provides the worldwide high-energy physics community with reference compilations of all existing particle data. The particle physics program has an active component in experimental and theoretical astrophysics, with emphasis on particle astrophysics at the boundary of particle physics and cosmology. In addition to the particle physics program, there is a smaller but highly significant research effort in applied mathematics.

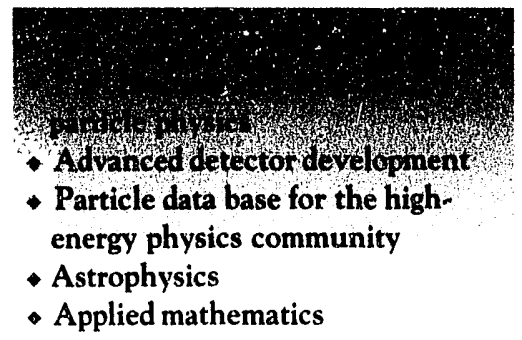

\section{Nuclear Science Divison}

The principal activity of the Division is the theoretical and experimental investigation of the interactions of heavy ions with target nuclei at various energies, both for their inherent scientific interest and for their use in the synthesis and study of new isotopes and chemical elements. This research program is carried out at LBL's accelerators and at other national and international accelerators. The Division operates the 88-Inch Cyclotron as a National User Cility. It fulfills an educational role with active graduate student and postdoctoral programs.

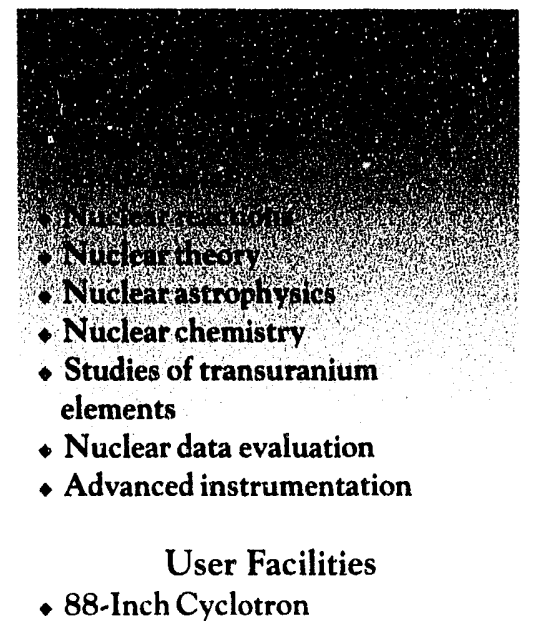

\section{Accelerator and Fusion Research Division}

The advanced technology of bean s-ions, electrons, and photons -is the focus of the Accelerator and Fusion Research Division. The Division is responsible for the operation of most of LBL's accelerators. Its scientists and engineers design new accelerators and devise new accelerator-technology applications ranging from fusion power tu cancer treatment. A major effort has been the design and construction of the Advanced Light Source (ALS), a state-of-the-art radiation tool. The ALS is a National User Facility available to qualified U.S. researchers.

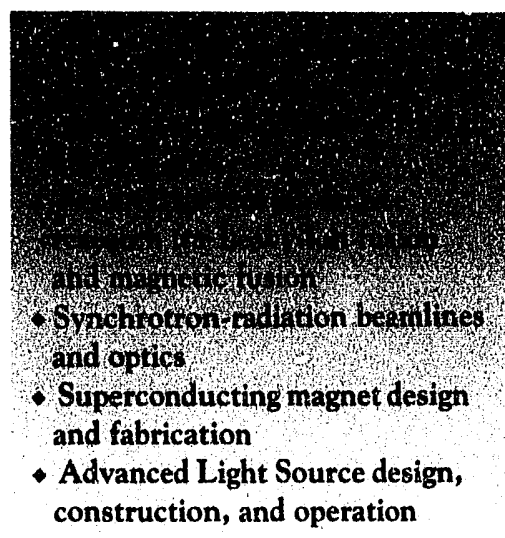

User Facilities

- Advanced Light Source (first operation 1993)

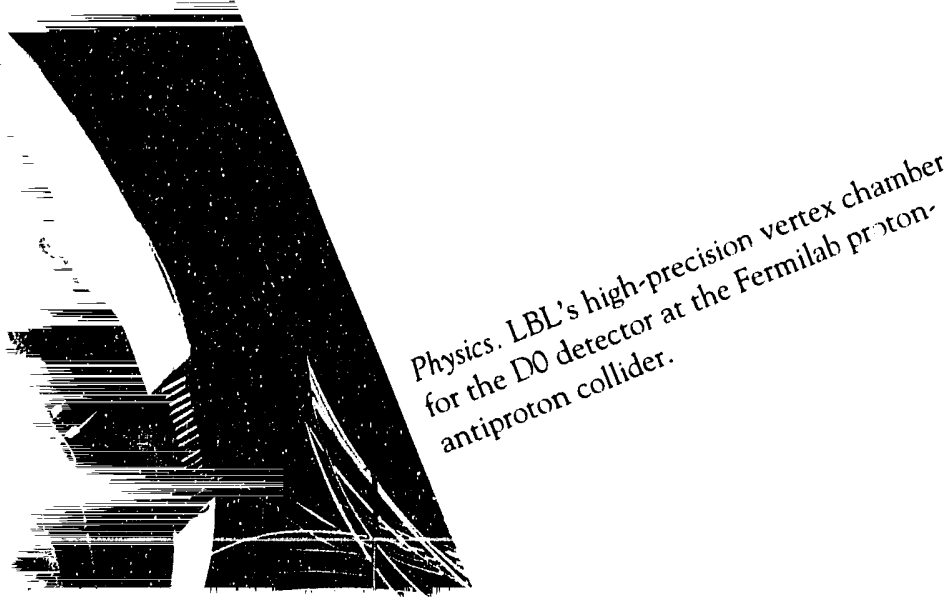




\section{BIOSCIENCES}

Through the development of biomedical instrumentation, studies of the intricate processes of gene expression, and expanding efforts to link biological structure and function, Biosciences research plays an important role in understanding biological processes and controlling disease.

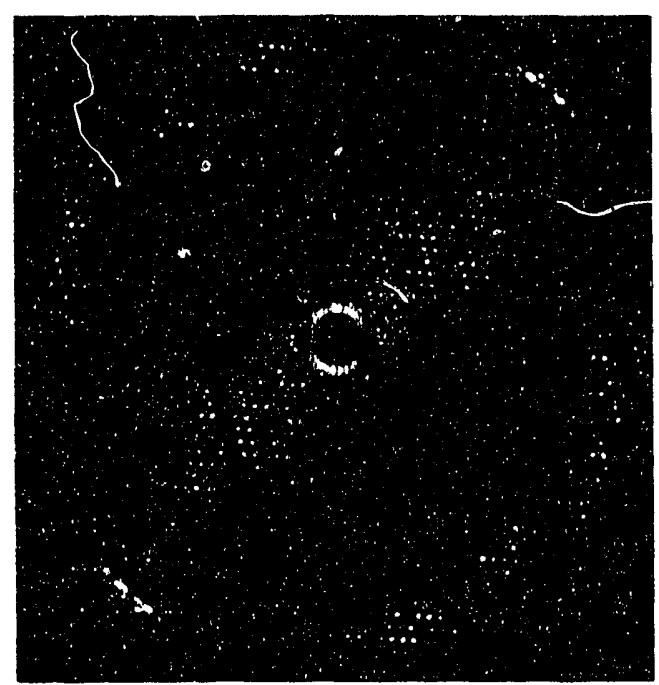

Life Sciences. PhoE porin, a transmembrane channel found in the outer membranes of Gram-negative bacteria. It has been reconstituted into highly coherent two-dimensional crystals using a novel crystallization technique.

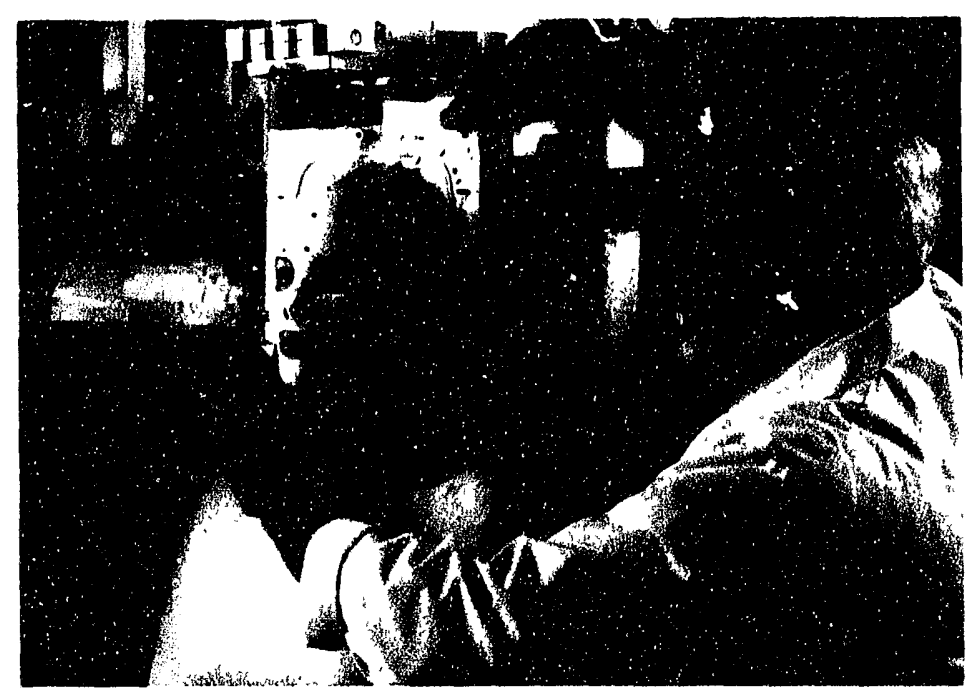

Life Sciences. LBL's patıent-immobilızation and heam-shapins system used in charged-particle radiation therapy.

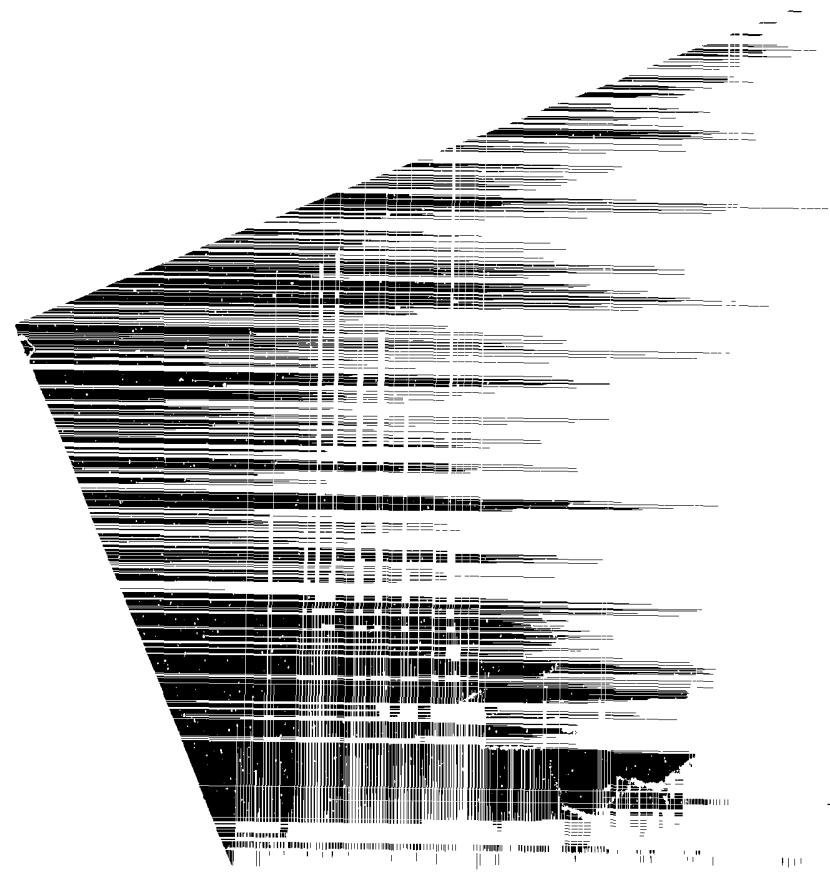




\section{Life Sciences Division}

The Life Sciences Division consists of three departments: Cell and Molecular Biology, Molecular and Nuclear Medicine, and Subcellular Structure. The Division is also home to the Human Genome Center (discussed under centers). One goal of the Division is to develop a deeper understanding of DNA replication and gene expression. This includes determining how tissue-specific genes are regulated in response to cues from their microenvironment, with a particular emphasis on breast cancer and hematopoiesis. Life Sciences investigators are studying the biological effects of DNAdamaging agents at a cellular and molecular level, as well as the health risks associated with such damage. The Diviston has developed new techniques in elucidating the organization and structure of membrane proteins and, in conjunction with the Advanced Light

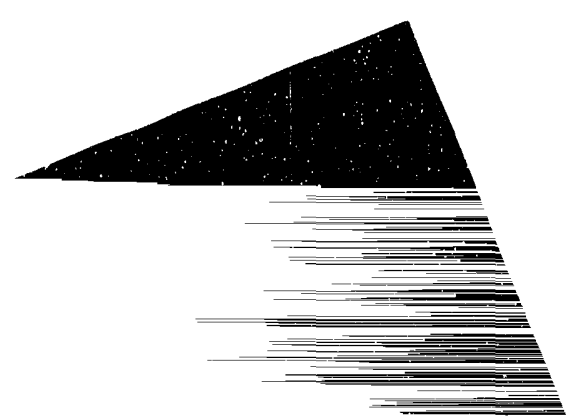

Source, has embarked on a program to determine the possible role of soft $x$-ray microscopy in characterizing subcellular structure.

Other important goals are the development and application of advanced procedures for the diagnosis and treatment of human disease, focusing on disorders of the cardiovascular system and the brain. Division researchers are designing and testing molecular and genetic probes for disease suscertibility, based on studies of mechanisms at the biochemical, cellular, and clinical levels; studying genetic variar its in humans and transgenic mouse models; and using the tools of nuclear chemistry and instrumentation to create improved diagnostic technologies for magnetic resonance imaging and positron-emission tomography, which are being applied in clinical research.

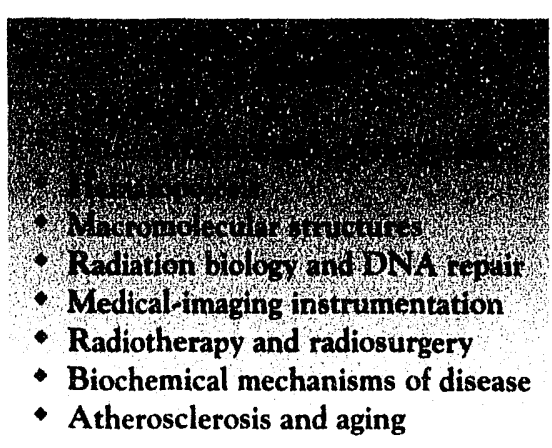

User Facilities

- Heavy Charged-Particle Biomedical Facility

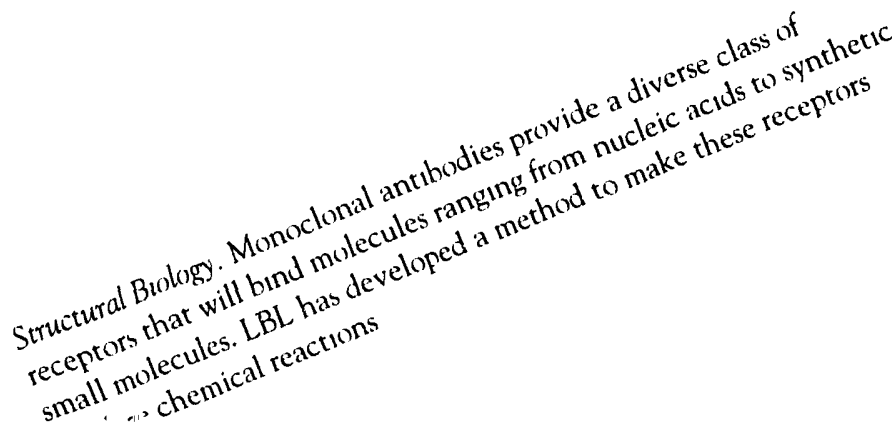

\section{Structural Biology Division}

Research work in Structural Biology contributes to the understanding of the relationship between structure and function in biological macromolecules. Projects include the study of the molecular mechanisms of photosynthesis and the involvement of structural modification of protein involved with oncogenesis. Nuclear Magnetic Resonance and $\mathrm{x}$-ray crystallographic techniques are used to probe the molecular structure of complex biomolecules and to study the fundamental chemistry of electronically excited molecules.

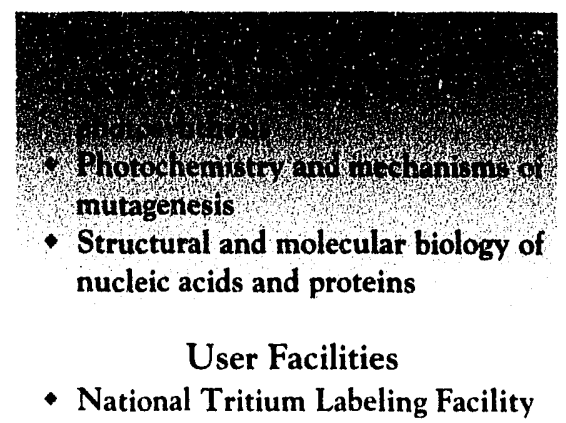

- National Tritium Labeling Facility 


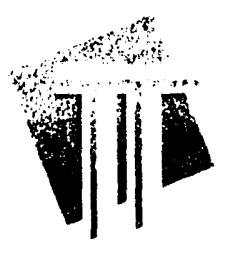

\section{LABORATORY OPERATIONS}

The Laboratory's Operations organization provides scientific and technical resources in support of LBL's research divisions. It provides engineering and computer science expertise to those divisions to accomplish the Lab's research goals. Its research programs yield innovative cutting-edge technology.

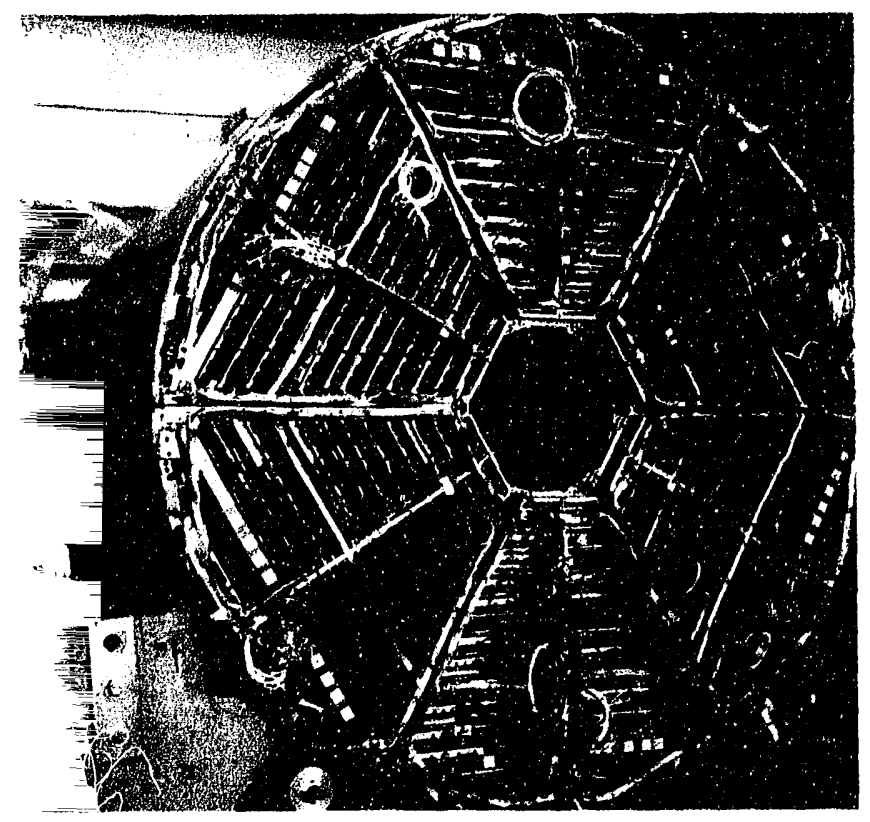

Engineering. The Time Projection Chamber (TPC), a particle detector invented at LBL that detects and identifies subatomic particles. The TPC reconstructs the three-dimensional ionization tracks of energetic subatomic particles over a time interval.

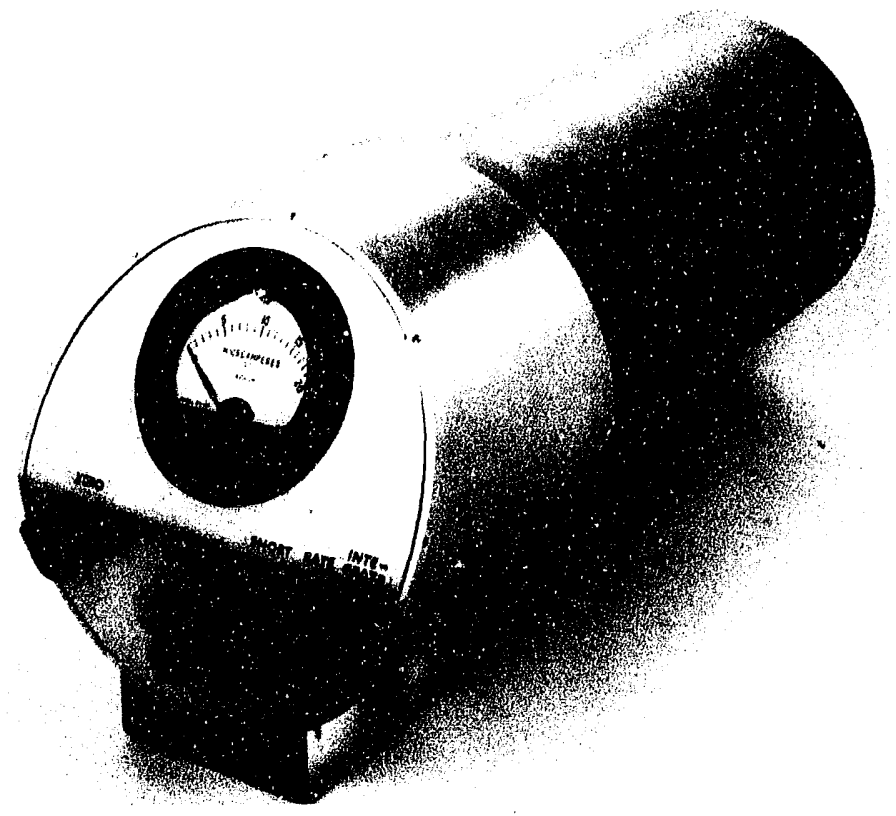

Environment, Health $\mathcal{E}$ Safety. This LBL-developed radiation detector measures the amount of ionizing radiation from such sources as radioisotopes, $\mathrm{x}$-ray generators, charged-particle accelerators, and natural background.

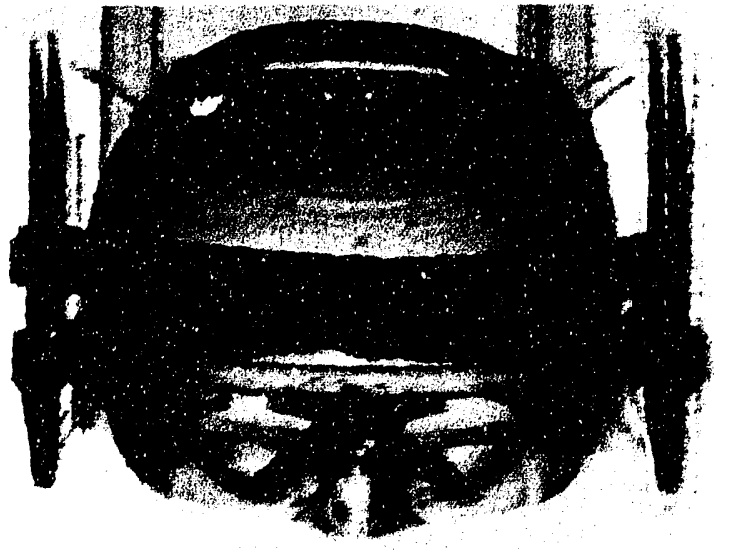

Information and Computing Sciences. An example of LBL's visualization and graphics work. The image shows the integration of two data sets: a head of a child via $x$-ray computer tomography, and the identification of a region of the brain to be treated. This work is being done with the Life Sciences Division. 


\section{Engineering Division}

Technica! resources to support the research programs and the major research facilities of LBL are provided by Engineering. Many engineers and technicians are assigned outside the Division as team members to the various programs and research facilities, bringing the expertise of the engineering disciplines to bear on the objectives of the research or operations teams. Two offices, Electronics and Mechanical Engineering, administer the outside assignments of personnel, operate the central electronics and mechanical shops, and conduct basic research in the fields of nuclear instrumentation,

semiconductor detectors, and magnet technologies.

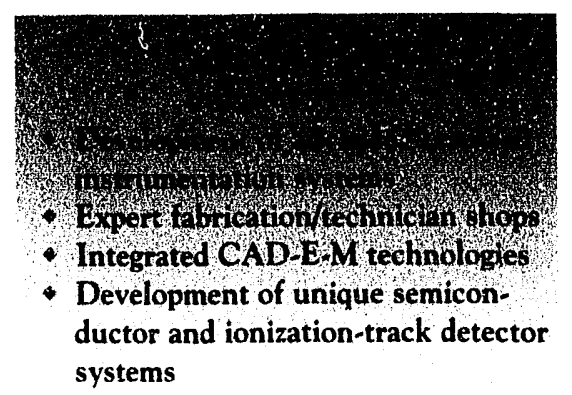

User Facilities

- Low-Background Counting Facility

\section{Information and Computing Sciences Division}

Information and Computing Sciences (ICS) operates computing and networking facilities, libraries, and technical publishing facilities to support LBL's scientific programs. ICS also conducts a program of computer science research and development in technologies appropriate for present and future scientific programs. This includes advanced software architectures, networking, data management, imaging, and visualization. An important aspect of the program is the evaluation of new hardware and software products and the integration of new technologies into scientific computing. ICS also provides application programs in several key areas, such as the Human Genome project and Biostatistics.

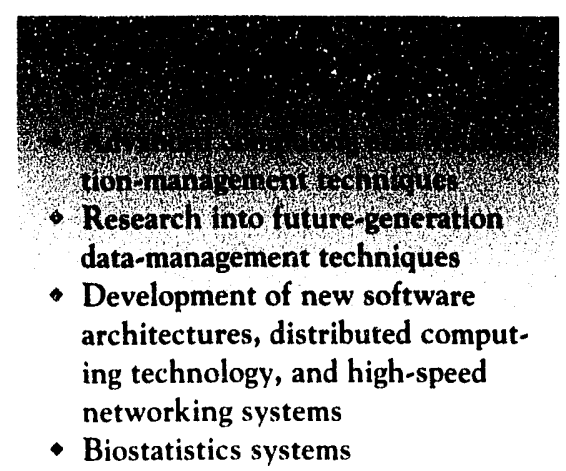

\section{Environment, Health \& Safety}

Environment, Health \& Safety $(E H \& S)$ is responsible for making sure that $L B L$ remains a safe and healithy work place. In addition to continuing advanced work in personal dosimetry, EH\&S has invaluable experience with radiation-protection systems for particle accelerators and is playing a major role in the design of these systems for new accelerators.

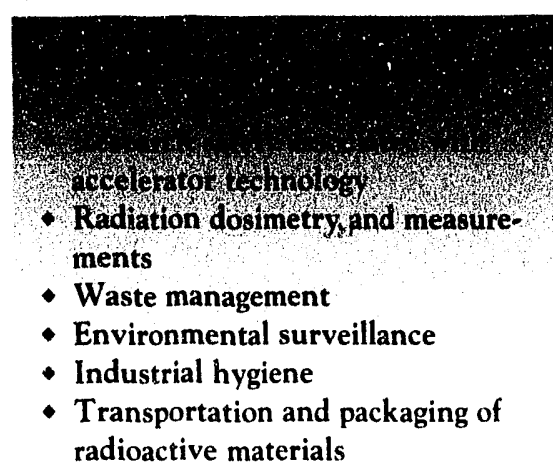




\section{Vili}

\section{Research Centers}

Lawrence Berkeley Laboratory has established multidisciplinary research centers with the specific objective of fostering research with industry and educational institutions. LBL's research centers apply skills, expertise, and instrumentation in many subject areas to specific research problems. Many centers focus on problems of special interest to the private sector. Each research center offers a unique multidisciplinary approach to research areas of national interest, all of which have a potential for positive impact on the American economy.

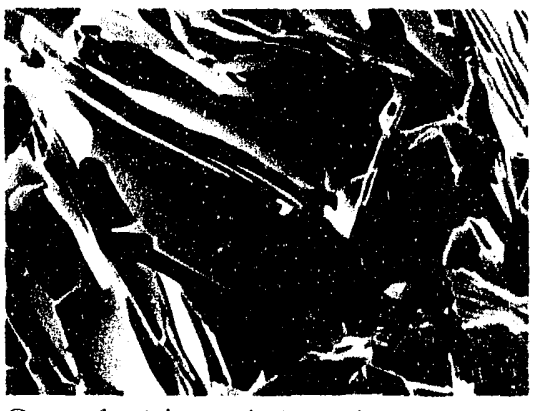

Center for Advanced Materials.

Scanning electron micrograph of a high-temperature superconductor made of bismuth-strontium-calcium-copper oxide.

\section{Center for Advanced Materials}

The Center for Advanced Materials (CAM) works in close partnership with industry and universities to perform fundamental materials science research in areas of prime importance to industry. CAM provides high-quality materials research that is directed toward the long-range needs of hightechnology energy-related disciplines. The major areas of research activity in the Center for Advanced Materials are

- High- $T_{c}$ superconductivity

- Electronic materials

- Polymers and composites, including enzymatic synthesis

- High-performance metals

- Surface science and catalysis including instrumentation for surface science

- Ceramic science

\section{Human Genome Center}

Activities at the Human Genome Center are concentrated in three areas: automation of existing physical mapping methods and development of new ones, evaluation and enhancement of existing sequencing technologies, and improvement of methods for interpreting and analyzing maps and sequence data. Current research endeavors within the three areas include

- Constructing an ordered library for chromosome 21

- Improving YAC cloning metlods

- Linking large DNA fragments and YACs by sequencing

- Improving pulsed-field gel electrophoresis

- Developing automated methods for image enhancement, image analysis, and map construction
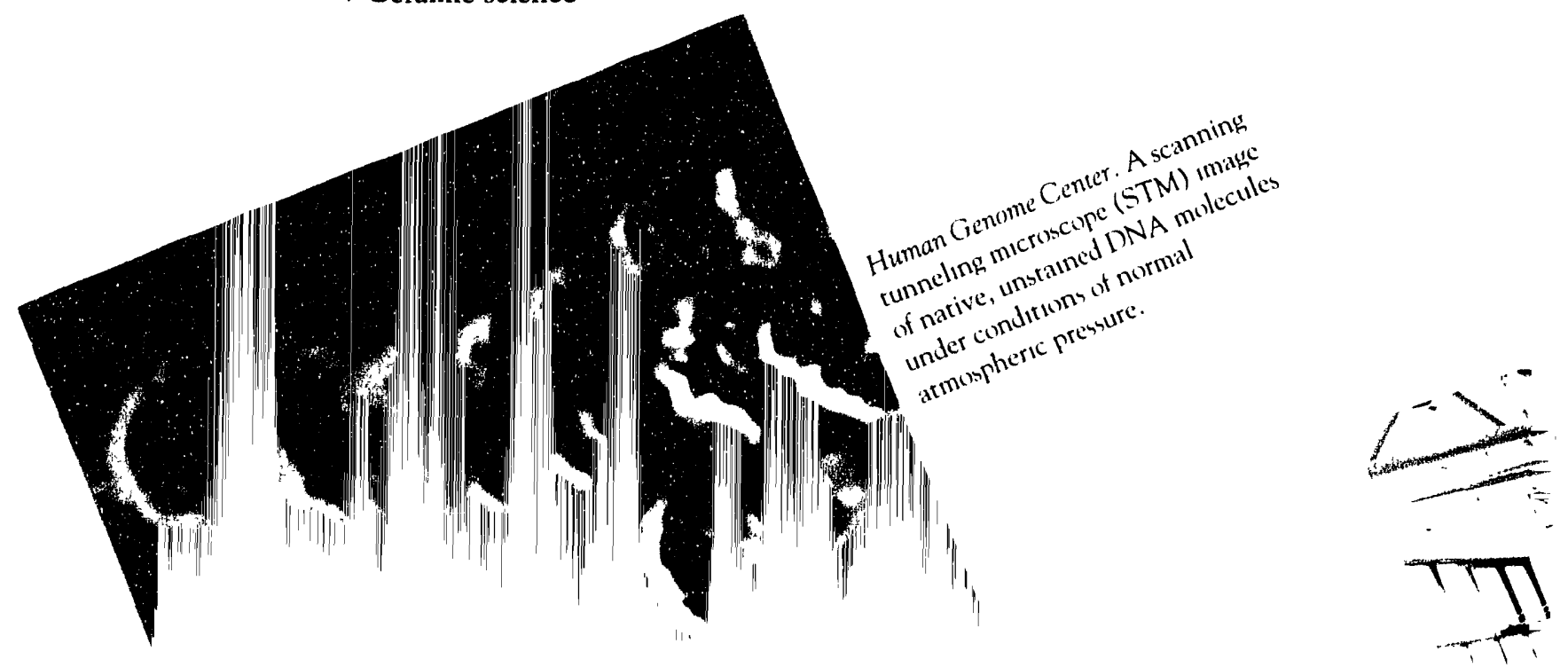


\section{Center for Building Science}

The Center for Building Science provides a cohesive working environinent to perform joint research, to develop new research areas, and to transfer successful building $R \& D$ results to industry. Windows, lighting, and daylighting: development of advanced, efficient lamps and controls; studies of human performance under varied lighting conditions; thin-film coatings and other approaches to advanced window design; window performance measurements and modeling. Indoor air quality: pollutant characterization and control; ventilation and infiltration; building performance monitoring; exposure assessment; sampling and analysis methods; predictive models. Systems and Analysis: DOE-2 whole-building energy analysis program and advanced simulation techniques; advanced HVAC systems; databases of measured building performance; environmental policy; appliance standards; Least Cost Utility Planning; international energy use.

\section{Center for X-Ray Optics}

The Center develops means for generating, transporting, focusing, and detecting radiation with photon energies from approximately $10 \mathrm{eV}$ to $10 \mathrm{keV}$. Continuing research programs include diffractive $x$-ray optics to develop $\mathrm{x}$-ray lenses for scanning and imaging materials, reflective $x$-ray optics to develop high-reflectivity multilayer coatings for hard $\mathrm{x}$-ray studies for materials and biological systems, monochromator and spectrometer development, highbrightness $\mathrm{x}$-ray source development, and $\mathrm{x}$-ray holography research. The Center conducts a wide range of research on the fundamental interactions of $x$-rays with matter and develops advanced beam lines at national synchrotron facilities, including the Advanced Light Source.

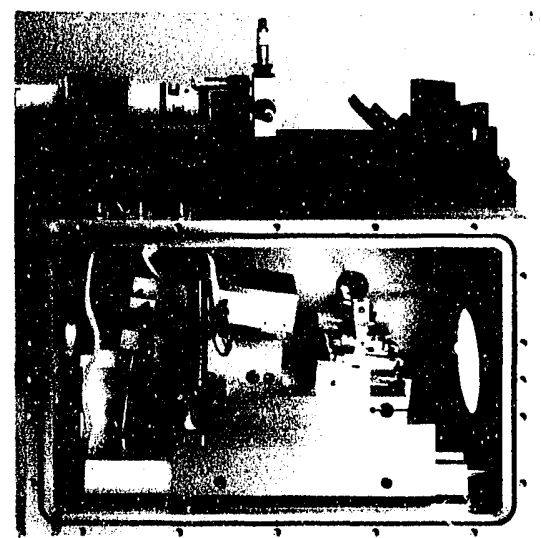

Center for X-Ray Optics. Designed at LBL, the High-Resolution Erect-Field Spectrometer/Monochromator analyzes electromagnetic radiation from the extreme ultraviolet and soft- $x$-ray regions.

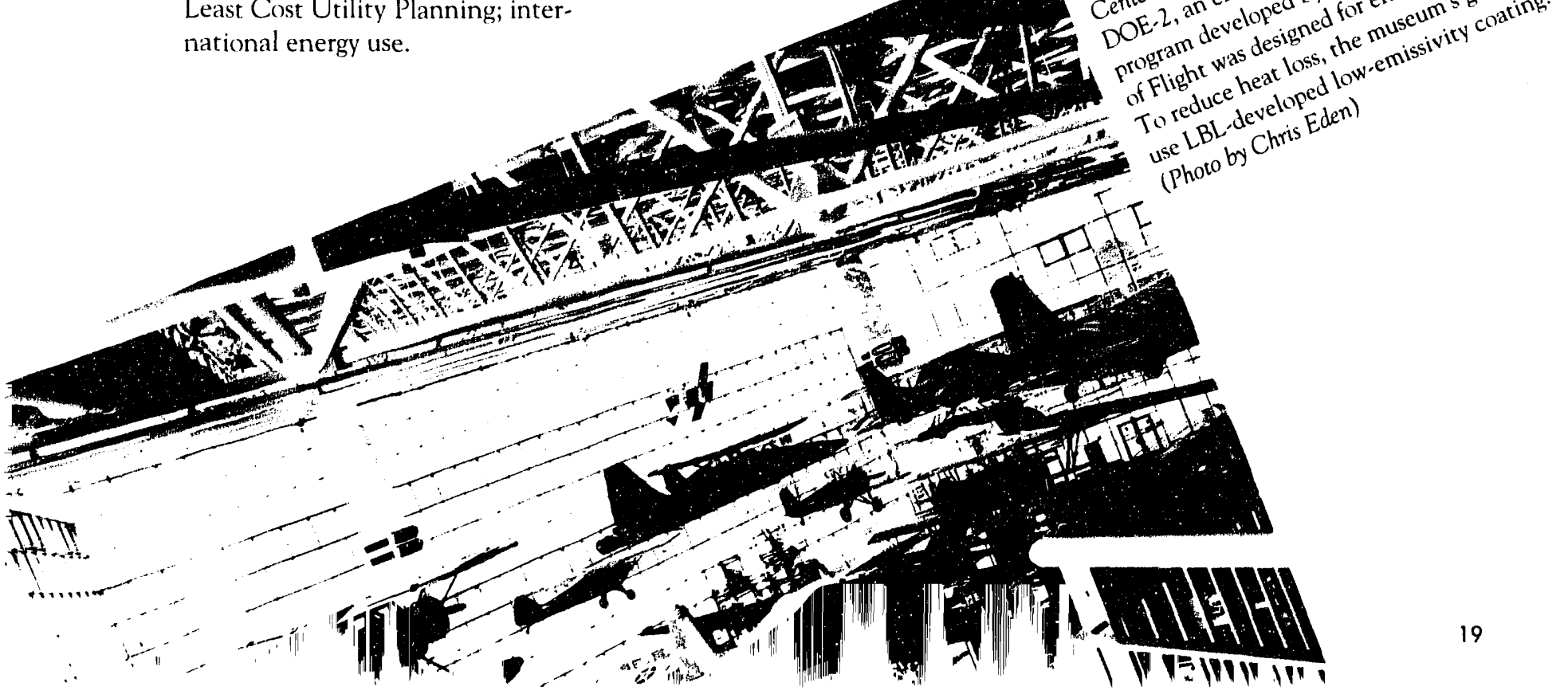




\section{Berkeley Electrochemical Researrh Sonter (BERC)}

The Berkeley Electrochemical Research Center carries out collaborative interdisciplinary research in the areas of electrochemical energy conversion and electrochemical enginerring. $\mathrm{BERC}$ is the Lead Center for the DOE's Technology Base Research Project for Electrochemical Energy Storage. The aim of this project is to advance the development of high-performance rechargeable batteries and fuel cells for applications such as electric vehicles and load levelıng. Center efforts include exploratory $R \& D$ on new electrochemical systems; supporting research for advanced rechargeable batteries; and electrochemical research to improve electrochemical energy-conversion efficiency and fuel-cell technology.

\section{California Institute for Energy Efficiency (CIEE)}

Hosted by LBL and financed through a Cooperative Research and Developmen.t Agreement (CRADA), CIEE is a collahorative scientific effort among the state's utilities, research institutions, and energy-related government bodies. Researchers from LBL's Energy and Environment Division and universities within California work on technology to improve the efficiency of energy use in the state. Through research to eliminate energy waste, CIEE focuses on alleviating such problems as urban smog, global warming, and the rising cost of and demand for electricity. CIEE's research seeks to reduce dependence on imported oil and avoid the need to construct new energy supply facilities, with their associated environmental impacts.

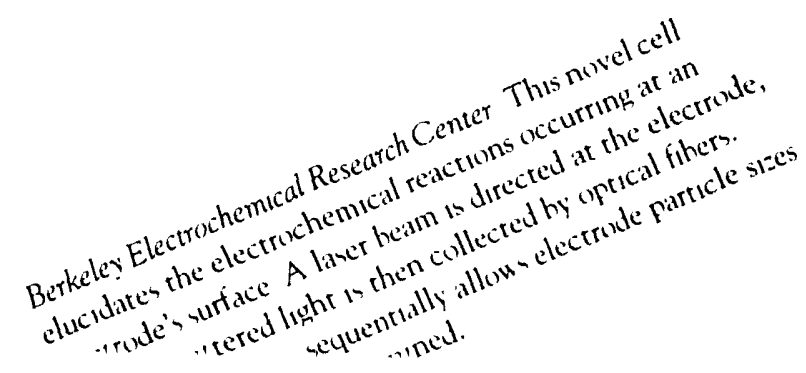




\section{Center for Isotope Geochemistry}

The Center for Isotope Geochemistry was established in the Earth Sciences Division. Assisting investigators around the world, Center scientists from LBL and UC Berkeley analyze geological materials and develop basic technologies and applications for precision measurement of geological isotopes. Isotope ratios can determine the age of sediments in petroleumhearing rock formations, elucidate past climatic conditions, and provide fundamental insights into the dynamics of hydrological systems for geothermal and environmental applications.

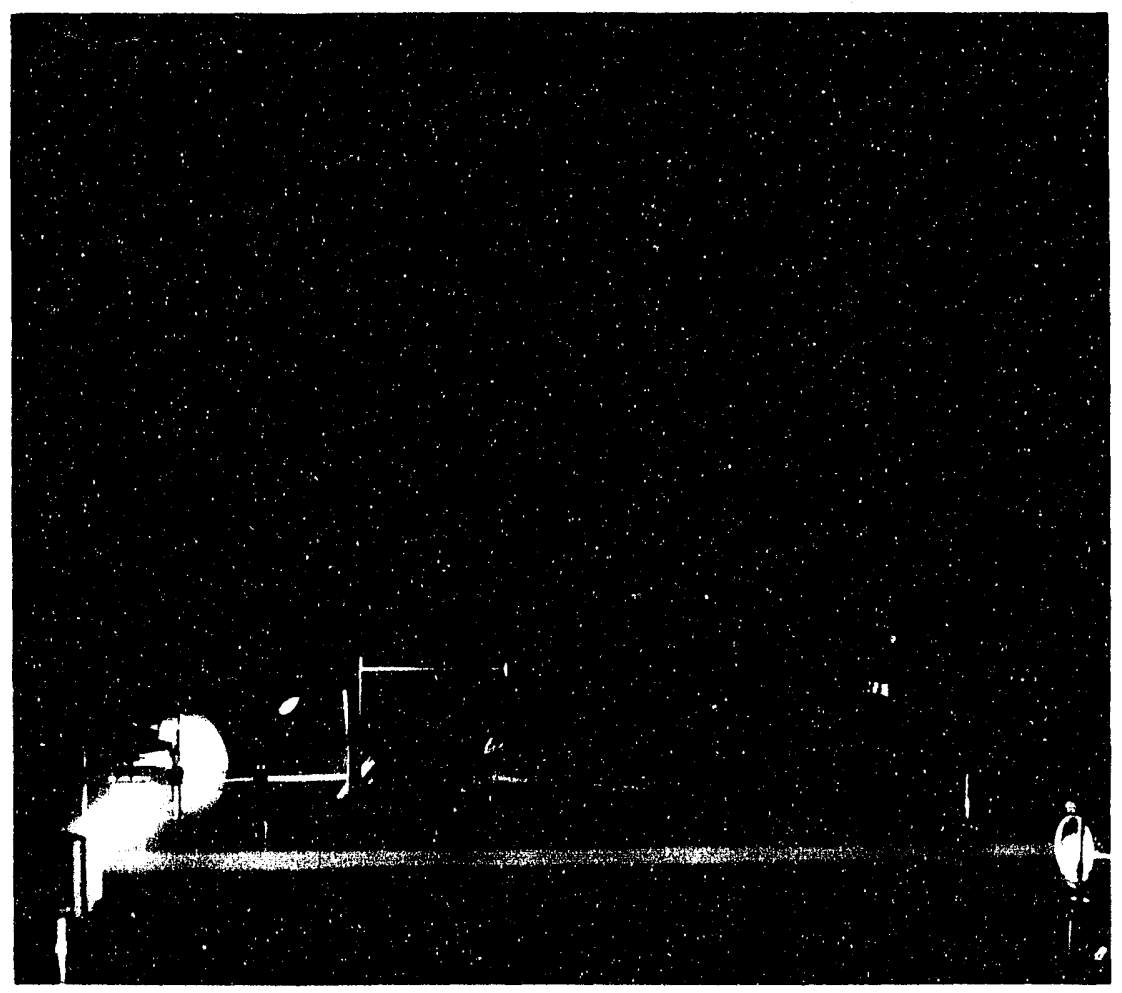

California Institute for Energy Efficiency. A researcher adjusts the laser diagnostics on the subscale hurner test stand at the UC Irvine Combus. tien Lahoratory. The laser diagnostics experiment is part of a project managed hy (.IEE to study ultralow NO, industrial natural gats hurners.

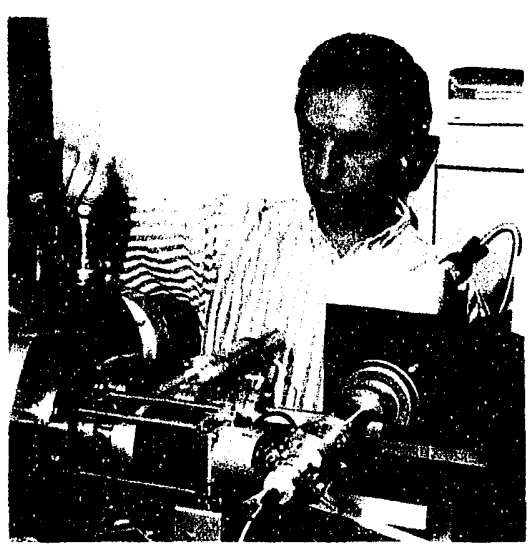

Center for Isotope Geochemistry. LBL researcher Don DePaolo uses a mass spectrometer to obtain precise measurements of isotopic ratios-information that holds clues to the geologic history of Earth.

\section{Center for Atmospheric and Biospheric Effects of Technology (CABET)}

Research within CABET focuses on the environmental effects of current and future innovations in technology. Emphasis is placed on studying the composition and behavior of direct emissions from particular technologies, as well as on developing the mechanisms for emission abatement. Also of interest to CABET are the health and ecological effects of these emissions as well as the global changes they may cause. 
LBL offers a range of unique research facilities to qualified investigators from universities, industry, and government. User Facilities designated as "National User Facilities" have national Program Advisory Committees to review research proposals by qualified investigators. DOE allows proprietary work by industry under some circumstances. Many sponsored projects take advantage of User Facilities.

\section{The 88-Inch Cyclotron}

The accelerator provides light ions, polarized protons and deuterons, and intense and high-charge-state beams of heavy ions at energies as high as $55 \mathrm{MeV}$ per nucleon. The cyclotron facility has experimental areas for conducting research in nuclear science, biomedicine, atomic physics, and radiation damage in semiconductors. A large complement of detectors located in the experimental areas includes a 21 . element array of Compton-suppressed high-resolution germanium

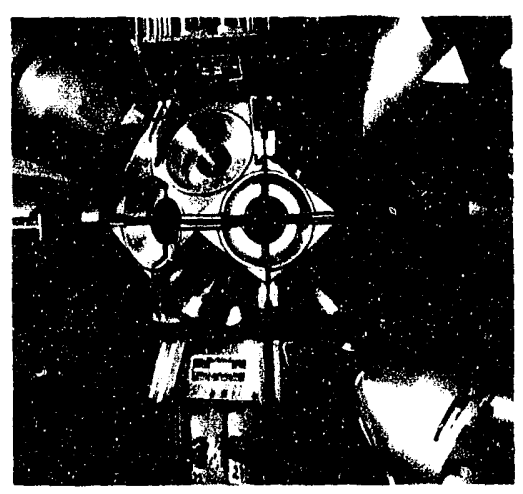

A view of the 21 Compton-shielded germanium $x$-ray detectors and the central bismuth germinate ball that make up the high-energy-resolution array. detectors for studies of nuclei at high spin, three large $\mathrm{NaI}$ gammaray spectrometers for a 60 -element particle hodoscope of phoswich detectors, a high-resolution magnetic spectrometer, a time-of-flight spectrometer, and an on-line isotope separator for studying exotic nuclei.

\section{The National Center For Electron Microscopy}

The Center operates two major transmission electron microscopes: The High Voltage Microscope ac-

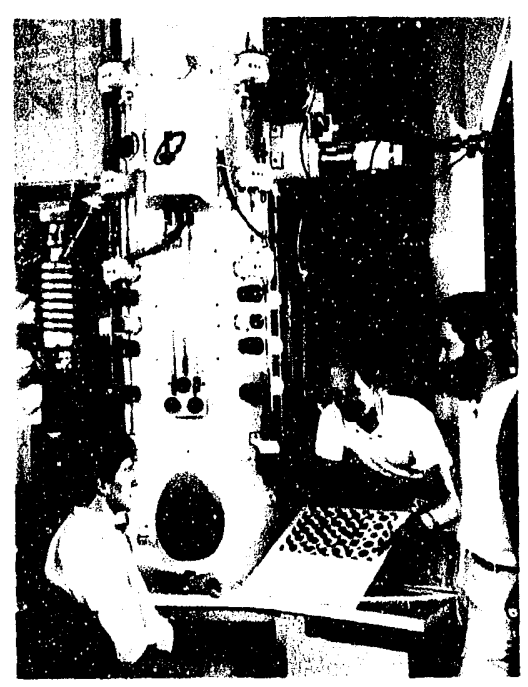

The Atomic Resolution Microscope offers the highest resolution of any microscope in the world (1.6 $)$. 
celerates electrons to energies of 1.5 MeV (the nost powerful microscope of its kind in the U.s.); the Atomic Resolution Microscope operates in the 0.4 to $1.0 \mathrm{MeV}$ range and offers the highest resolution in the world. The two microscopes allow materials scientists and hiologists to study samples under the most realistic conditions possible and to distinguish individual atom columns even in closely packed metallic and ceramic structures. A third microscope, the Analvtical Electron Microscope, operates at $0.2 \mathrm{MeV}$ and provides stare-of-the-art microanalytical capabilities.

\section{The Advanced Light Source (ALS)}

Scheduled tor initial operation in 1993, the ALS will provide photon beams of unprecedented brightness and cohcrence and with 30-psec time structure. With it, materials scientisis will tackle questions that can lead to new generations of semiconductor devices; chemists will be able $u$ study chemical reactivity at a new level of precision, and biologists plan to watch processes unfold in living cells.

\section{The National Tritium Labeling Facility (NTL.F)}

In this facility, compounds are labeled with tritium to serve as tracers it chen ical and biomedical reseaı $h$. The tritium-labeled compounds are then used by researchers at their home laboratories. Labeling is acromplished by microwave discharge, catalytic tritio hydrogenation, iodo displacements, and catalvtic exchanges. A significant activity of the NTLF is the training of scitatists $i_{2}$ the safe handling and use of tritium.

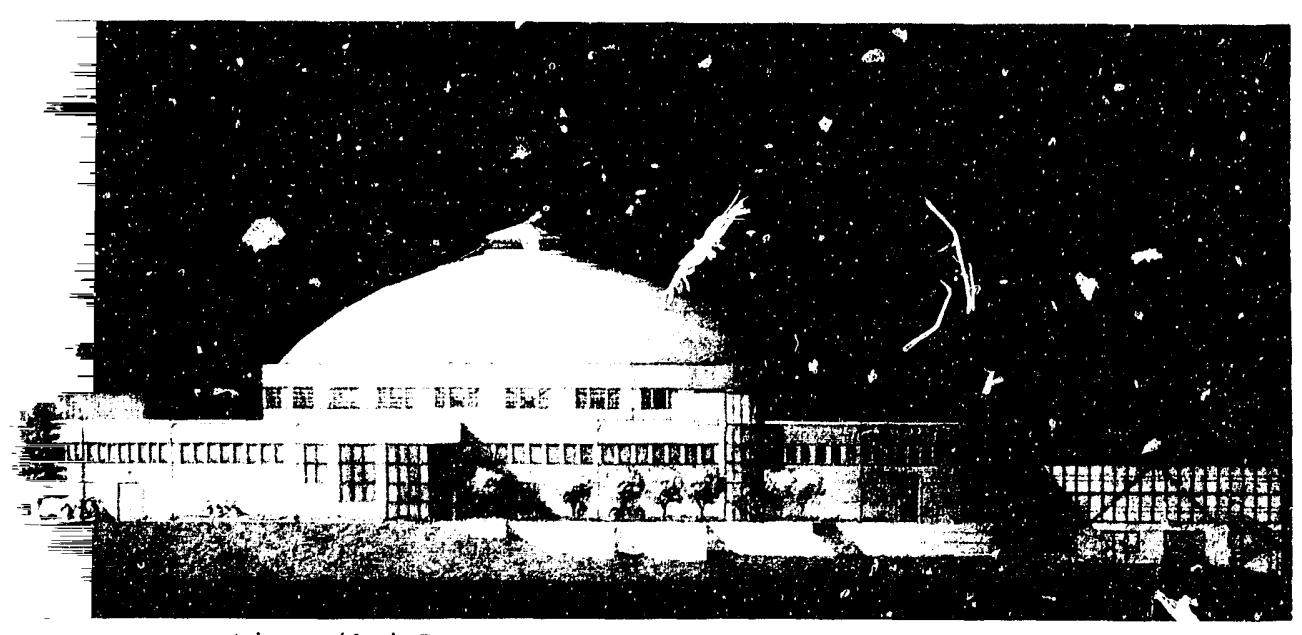

Advanced Light Source 


\section{Key To Lbl Buildings}

Bldg.

No.

\section{Occupants}

2 Advanced Materials Laboratory; Center for X-Ray Optics

Magnetic Fusion Energy

Magnetic Fusion Energy

Advanced Light Source

Stores; Electronics Shops

10 Lite Sciences; Photographic Services

14 Accelerator \& Fusion Rescarch; Earth Sciences

16 Magnetic Fusion Energy Laboratory

17 Environment, Health \& Safety; Energy \&

Environment Lab

25 Mechanical Technology

25A Electronics Shop

26 Medical Services

27 High-Voltage Test Facility \& Cable Shop

29 Electronics Engineering; Life Sciences

31 Chicken Creek Maintenance Building

40 Electronics Development Lah

41 Magnetic Measurements Lab

42 Salvage

44 Indoor Air Pollution Studies

45 Fire Apparatus

46 Advanced Light Source; Accelerator Develupment; Systems Engineering

46A Systems Engineering

47 HIFAR Group

48 Fire Station

50 Physics; Accelerator \& Fusion Research; Nuclear Science

50A Physics; Directur's Office; Planning \& Development; Administration; Patents; Earrh Sciences

$50 \mathrm{~B}$ Physics; Information and Computing Sciences; Telephene Services

50c: Public Information: Earth Sciences

501) Nuclear Science

50E Earth Sciences

50F Technical lllustration; Computing Resources

52 Magnetic Fusion Energy Lahuratory

53 SuperHILAC Development

54 Cafeteria

55 Life Sciences

55A Nuclear Magnetic Resonance

56 Cryogenic Facility

58 Accelerator Reseatch \& Development

58A Accelerator Research \& Development Lat

60 Physics High Bay Lahoratory

62 Materials Sciences; Chemical Sciences

63 Acceleratur \& Fusion Research

64 Accelerator \& Fusion Research

65 Data Processing Services

66 Chemical Sciences; Materials Sciences; Surface Science \& Catalysis Laboratory

69 Materiel Management \& Purchasing; Mailrom
Bldg.

No.

Occupants

70 Nuclear Science; Energy \& Environment; Earth Sciences

$70 \mathrm{~A}$ Nuclear Science; Chemical Sciences; Earth Sciences

71 Heavy lon Linear Accelerator (HIl.AC)

$71 A$ HILAC Rectifier; Exploratory Studies Group

$71 \mathrm{~B}$ HILAC Annex

72 National Center for Electron Microscony

72A High-Voltage Electron Microscone

72B Atomic Resolution Microscope

72C ARM Support Lath

73 Atmospheric Acrosol Research

74 Life Sciences

75 Radioisotope Services; National Tritium Facility

76 Construction \& Maintenance Craft Shops

77 Mechanical Shops

77A Ultrahigh Vacuum Assembly

78 Craft Stores

79 Metal Stores

80 Advanced Light Source Operations (future)

$80 \mathrm{~A}$ Advanced Light Source

81 Liquid (ias Storage

83 Cill Biology Laboratory

88 88-Inch Cyclutron

90 Energy \& Environment; Employment; Engineering; Personnel; Protective Services; Technology Transfer; Environment, Health \& Safety; Center for Science \& Engineering

Education

UCCAMIPUS BUILDINOS

WHOLLY OR PARTIALLY OCCUPIEI) BY LBL

1 Donner Lahoratory

3 Calvin Chemical Biondynamics Lahoratory

8 Hearst Mining

18 Gilman Hall

19 LeConte Hall

19 A Birge Hall

21 Giauque Hall

22 Latimer Hall

24 Etcheverry Hall

38 Lewis Hall

39 Cory Hall

905 Hesse Hall

983 Wurster Hall

984 Davis Hall

Not shown

Life Sciences "uilding

(near the western edge of the campus) 


\section{Lbl Map}

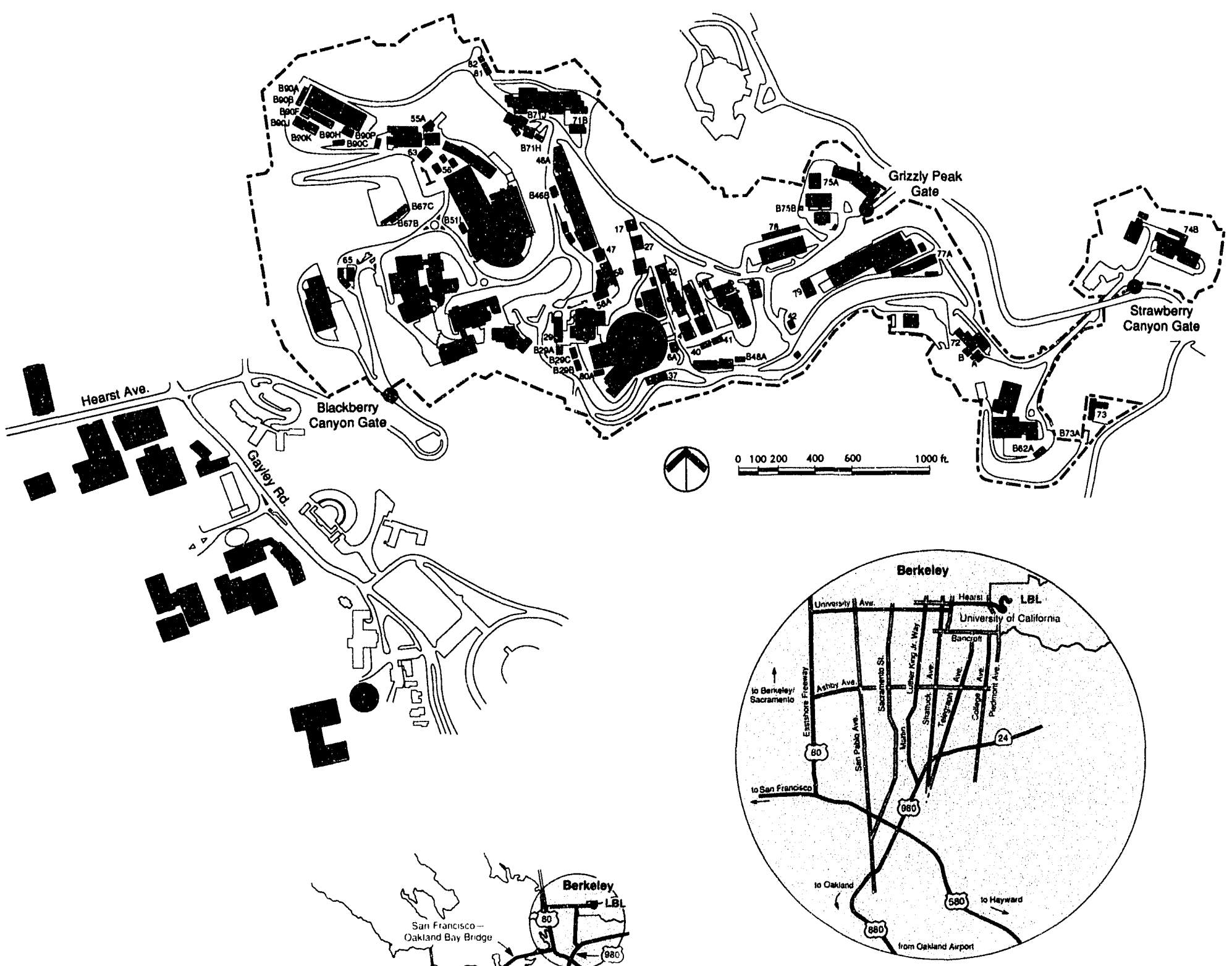

LRL, to San Francisco airport distance: $25 \mathrm{mi}$. driving time: $1-2 \mathrm{hr}$.

LBL, to Oakland airport distance: $16.5 \mathrm{mi}$. driving time: $1-1.5 \mathrm{hr}$.

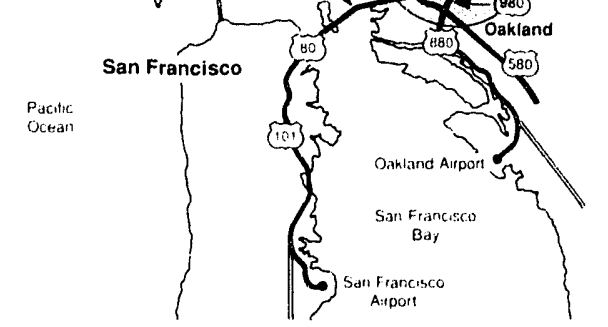

LBL is adjacent to the UC Berkeley campus.

There is shuttle bus service every

10 min. to the campus and to the downtown Berkeley BART station.

\section{LBL to Interstate 80 distance: $3 \mathrm{mi}$. driving time: $15 \mathrm{~min}$.}

Map indicates key streets only. 

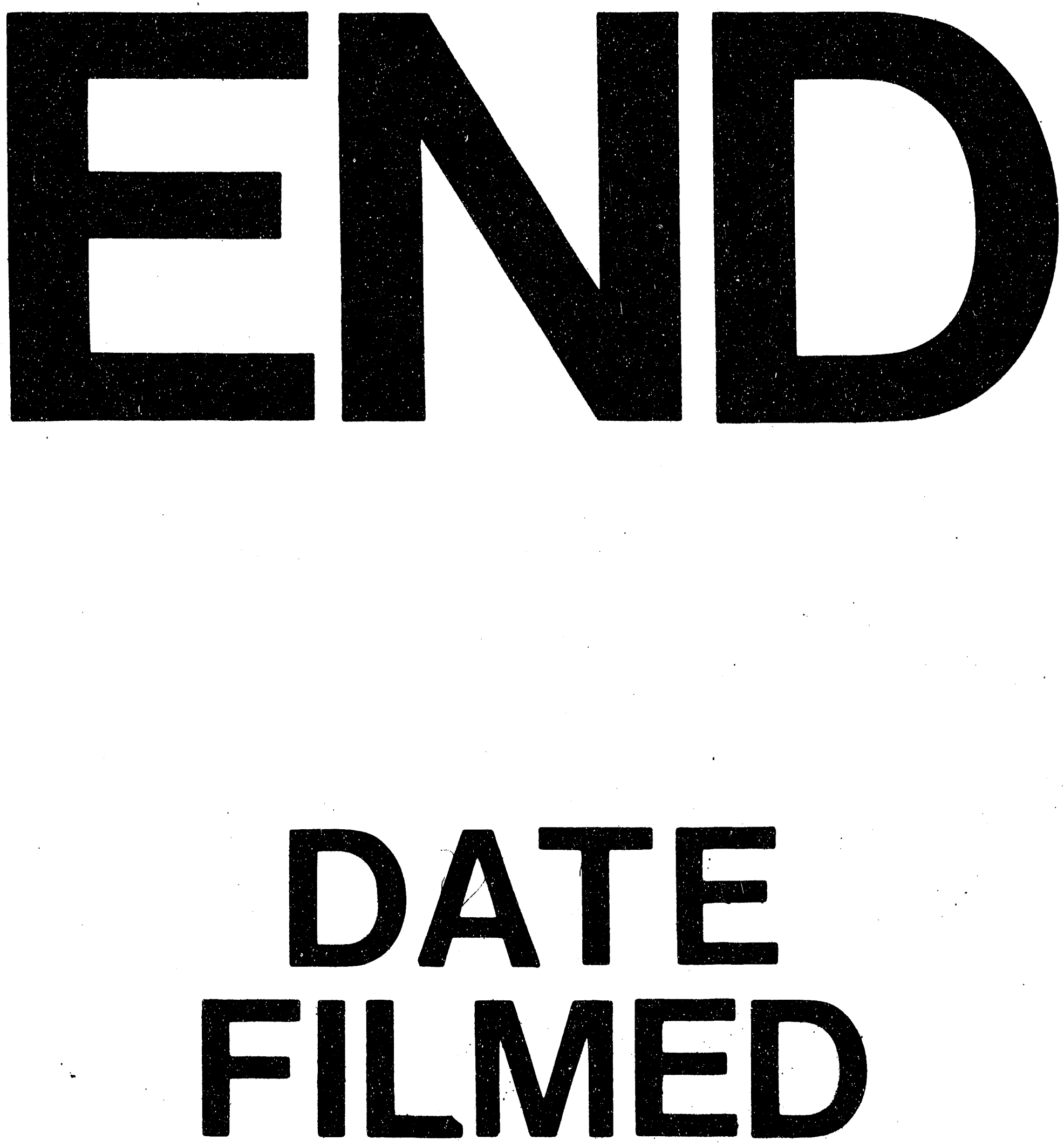

I

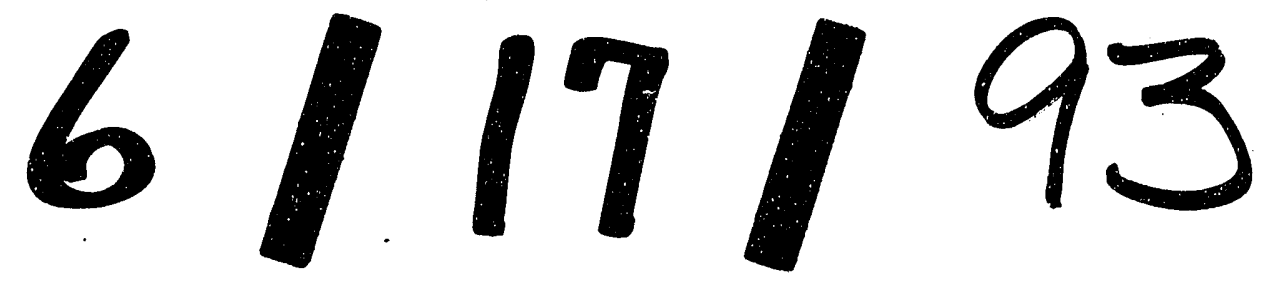


